\title{
LA CLÁUSULA DE HOMOGENEIDAD EN EL TRATADO DE LA UNIÓN EUROPEA Y EN LA CONSTITUCIÓN EUROPEA*
}

\begin{abstract}
POR
STELIO MANGIAMELI

Catedrático de Derecho constitucional en la Università degli Studi di Teramo (Italia)

\section{LA APARENTE DIVERSIDAD DE CONTENIDO DE LA HOMOGENEIDAD DEL TRATADO DE LA UNIÓN EUROPEA (TUE) Y DE LA CONSTITUCIÓN}

Cualquiera que efectúe una lectura coordinada del artículo 6.1 TUE y del artículo l-2 del Tratado por el que se establece una Constitución para Europa, no dejará de apreciar de inmediato la diversidad de contenidos y de estilo que, más allá del contexto y del valor simbólico, presentan las dos disposiciones: la primera se construye mediante elementos exclusivamente jurídicos $y$, no por casualidad, el incipit del texto reclama como fundamento de la Unión los "principios»" ${ }^{1}$; en cam-
\end{abstract}

* Traducción del original italiano por Luis Jimena Quesada (Universitat de València).

1 Art. 6.1 TUE: "La Unión se basa en los principios de libertad, democracia, respeto de los derechos humanos y de las libertades fundamentales y el Estado de Derecho, principios que son comunes a los Estados miembros». Sirven de corolario al principio de homogeneidad sintetizado por la disposición de referencia, de un lado, los otros párrafos del artículo 6 , relativos a los derechos fundamentales (pár. 2), a la identidad nacional (pár. 3) y a los denominados «medios necesarios» (pár. 4) y, de 
bio, la segunda haría pensar en la inclusión en la Constitución de un contenido metajurídico y, en tal sentido, el fundamento de la Unión haría referencia a "valores»².

otro lado, las disposiciones de los artículos 7, 46 (letra 3) y 49 TUE, relativos a la posibilidad de imponer sanciones a los Estados miembros que infrinjan los principios de la cláusula de homogeneidad, a la justiciabilidad de las disposiciones de carácter procedimental (contempladas en el artículo 7 TUE) ante el Tribunal de Justicia y a la adhesión de nuevos Estados a la Unión sobre la base del respeto de los principios del artículo 6.1 TUE.

2 Art. I-2 del Tratado constitucional: "La Unión se fundamenta en los valores de respeto de la dignidad humana, libertad, democracia, igualdad, Estado de Derecho y respeto de los derechos humanos, incluidos los derechos de las personas pertenecientes a minorías. Estos valores son comunes a los Estados miembros en una sociedad caracterizada por el pluralismo, la no discriminación, la tolerancia, la justicia, la solidaridad y la igualdad entre mujeres y hombres". En el texto de la Constitución europea están presente los mismos principios previstos por los párrafos 2, 3 y 4 el artículo 6 y de las disposiciones concordantes (artículos 46 y 49 ) del TUE, pero en un contexto sistemático diverso: por ejemplo, con respecto a los derechos, véase el Título II y, en particular, el artículo I-7 (incluida la remisión a la Parte II de la Constitución, que incorpora la Carta de los derechos); con relación a la identidad de los Estados miembros, el principio se reconoce en el ámbito de las reglas que disciplinan las relaciones entre la Unión y los Estados miembros; véase el art. I-5.1, pero puede añadirse asimismo la previsión según la cual "La Unión respetará la riqueza de su diversidad cultural y lingüística y velará por la conservación y el desarrollo del patrimonio cultural europeo" (art. I-3.3, párrafo 3); en lo atinente a la autonomía financiera, véase el art. I-53.1 sobre los recursos propios de la Unión. El aparato sancionador de la cláusula de homogeneidad (art. 1-59) viene disciplinado en el ámbito del Título IV, relativo a la pertenencia a la Unión, junto con la disposición sobre la admisibilidad y el procedimiento de adhesión a la Unión (art. I-58), mientras la específica competencia del Tribunal de Justicia ha sido incluida en el núcleo de las atribuciones de esta institución en la Parte III de la Constitución (art. III-371). A continuación, repárese en que los caracteres del principio de homogeneidad contenidos en el texto de la Constitución cuentan con una disciplina exhaustiva, a veces explícita, como ocurre ahora con el principio democrático, que ha sido ubicado en el Título VI de la Parte I, englobando en él también el principio de proximidad (Todo ciudadano tiene derecho a participar en la vida democrática de la Unión. Las decisiones serán tomadas de la forma más abierta y próxima posible a los ciudadanos). Se revela bastante significativa en este contexto la previsión según la cual «El funcionamiento de la Unión se basa en la democracia representativa", con la directa representación de los ciudadanos (todos) confiada al Parlamento europeo y la de los Estados miembros atribuida al Consejo europeo, a través de la presencia de los respectivos Jefes de Estado o de Gobierno, o al Consejo a través de los respectivos Gobiernos, "que serán democráticamente responsables, bien ante sus Parlamentos nacionales, bien ante sus ciudadanos" (art. I-45). En otras ocasiones, la manifestación de los caracteres del principio de homogeneidad se desprende de la interpretación sistemática, como en el caso del principio del Estado de Derecho, que aparece 
Se trata, sin embargo, de una diferencia más aparente que real, puesto que en cada norma subyace una opción de carácter axiológico, además de que un aspecto típico del Derecho consiste precisamente en cubrir con el manto de la juridicidad elementos que son propios de la realidad social, en cuyo núcleo se inscriben asimismo los valores.

Por otra parte, mientras no parece posible desde el punto de vista de la epistemología del Derecho un retroceso de los principios a los valores $^{3}$, la inclusión en un texto legislativo o (con mayor motivo) constitucional de "valores" tiene el efecto de juridificarlos y de reconducirlos al núcleo del Derecho, de suerte que éstos, una vez normativizados, se transforman naturalmente en "principios" $y$, como tales, susceptibles de interpretación y de formar sistema ${ }^{4}$.

En todo caso, la diferencia que parece manifestarse entre los dos textos considerados puede reconducirse a otro aspecto. En el texto del Tratado de la Unión Europea el principio de homogeneidad aparece expresado de modo reconocible; diversamente, en la forma asumida en el artículo I-2 de la Constitución europea, junto a los aspectos relativos al reconocimiento de las experiencias precedentes, se habrían insertado perfiles nuevos y de carácter programático, esto es, tendentes a regular los comportamientos futuros, ya sea de la Unión, ya sea de los Estados miembros. En efecto, la disposición de referencia, además de afirmar que "la Unión se fundamenta en los valores de respeto de la dignidad humana, libertad, democracia, igualdad, Estado de Derecho y respeto de los derechos humanos, incluidos los derechos de las personas pertenecientes a minorías", declarando que "estos valores son comunes a los Estados miembros", habla -innovando el principio de homogeneidad del TUE- de «una sociedad caracterizada por el pluralismo, la no discriminación, la tolerancia, la justicia, la solidaridad y la igualdad entre mujeres y hombres", dejando entender que las activi-

dotado de mayor vigor en el ordenamiento de la Unión esencialmente con apoyo en las normas que disciplinan la justicia europea (véase la Parte III, sección 4 del Capítulo IV, del Tratado constitucional), en particular el art. III-270 (sobre el control de legitimidad) y el artículo III-274 (sobre la cuestión prejudicial).

3 Este punto resulta decisivo en la interpretación jurídica en general y, específicamente, en la interpretación constitucional, dado que las técnicas que propician una reconducción de las normas (principios) a los valores (véase R. ALEXY, Theorie der Grundrechte, Frankfurt a.M., 1986, 125 ss.), alterando los efectos del proceso de Verrechtlichung, metodológicamente acaban sustituyendo la vinculación a la ley (rectius: al Derecho) por el arbitrio del poder decisor de turno.

4 A tal efecto, véase A. D'ATENA, I principi e i valori costituzionali, en Lezioni di diritto costituzionale, Torino, 2001, 1 ss.. 
dades de las Instituciones y de los Estados miembros se orientan en una determinada dirección ${ }^{5}$.

Esta segunda parte de la disposición, por ende, puede ser considerada más propiamente como un bloque de objetivos a perseguir conjuntamente en el ordenamiento europeo y en los ordenamientos de los Estados miembros, y como tal podía haber sido perfectamente consignada en el artículo I-3 del Tratado constitucional, no resultando casual que éste recuerde inmediatamente entre las realizaciones que la nueva Constitución debería asegurar la promoción, en el ámbito interno (pár. 1) y en el exterior (pár. 4) de los "valores" de la Unión.

Pero incluso esta parte dinámica del nuevo principio de homogeneidad —como se verá- no altera su estructura ni el carácter específicamente jurídico que éste reviste en el sistema constitucional europeo y, particularmente, en las relaciones entre Instituciones y Estados miembros. En efecto, las finalidades consignadas en la disposición sobre "valores" de la Unión constituyen una contribución significativa a la superación de las diferenciaciones internas que se consideren incompatibles con la estructura del conjuto del sistema ${ }^{6}$.

${ }^{5}$ Sobre el principio de homogeneidad, véase H.P. IPSEN, Über Verfassungs-Homogenität in der Europäischen Gemeinschaft, en Das akzeptierte Grundgesetz, FS für Günter Dürig, München, 1990, 159 ss.; F. SCHORKOPF, Homogenität in der Europäischen Union - Ausgestaltung und Gewährleistung durch Art. 6 Abs. 1 und Art. 7 EUV, Berlin, 2000; V. CONSTANTINESCO, L'intégration des principes constitutionnels nationaux dans le Traité: I'article 6 \& 1 du Traité sur I'Union (ex- $F$ \& 1), tel que modifié par le Traité d'Amsterdam, en Droit constitutionnel Droit communautaire. Vers un respect réciproque mutuel ?, Paris, 2001, 299 ss.; V. ATRIPALDI - R. Miccù (coords.), L'omogeneità costituzionale nell'Unione Europea, Padova, 2003. Sobre las disposiciones referentes a la homogeneidad en el entonces proyecto de Constitución europea, véase asimismo J. WüRMELING, Entwurf des Europäischen Verfassungsvertrages. Erster Bericht zu den Ergebnissen des EU-Verfassungskonvents, Brüssel/Bayreuth, den 13. Juni 2003, 7 s., el cual subraya que "die Werte und Ziele spiegeln daqs christliche Menschenbild sowie die Grundsätze von Demokratie, Rechtstaatlichkeit und Solidarität widern; C. PINELLI, II preambolo, i valori, gli obiettivi, en Una Costituzione per l'Europa, a cura di F. Bassanini e G. Tiberi, Bologna, 2004, 33 ss., che vede nei valori "las cifras identificativas del ordenamiento", que "preceden a los objetivos y los orientan".

${ }^{6}$ De manera análoga a lo que prescribió la Constitución italiana en el artículo 3.2, atribuyendo a la República el deber de remover los obstáculos de orden económico y social. 


\section{LA NATURALEZA EXCLUSIVAMENTE JURÍDICA DE LA HOMOGENEIDAD Y EL CARÁCTER SOCIOLÓGICO DE LOS PRESUPUESTOS}

Sobre la base de esta premisa, que no pretende minusvalorar las innovaciones producidas por la Constitución europea en el ámbito específico tomado en consideración sino simplemente subrayar la continuidad de la presencia de un "principio de homogeneidad" en el ordenamiento constitucional europeo, se plantean todas las cuestiones relativas al alcance y al carácter, a la formulación y a la función del mismo principio.

En tal sentido, la primera cuestión a solventar afecta al ámbito de pertenencia de la homogeneidad. En efecto, es objeto de controversia si ésta es una categoría jurídica o una cláusula general (Ventilbegriffe) que abre la interpretación a la ponderación de condiciones materiales y sociales ${ }^{7}$. Esta problemática, que en ocasiones aparece renovada asimismo con motivo del tema, considerado especulativo, de la identidad (de la Unión y de los Estados miembros), conlleva siempre plantearse siempre la cuestión en torno al orden de importancia en el que la homogeneidad (y la identidad) se sitúa (sitúan): si en el deontológico (Sollen), o en el existencial (Sein). De hecho, es de sobra conocido que la compatibilidad de reglas y actos jurídicos, en la que al final desembocaría la homogeneidad, puede reputarse posible - ya sea en un ordenamiento estatal unitario, ya sea en un sistema caracterizado por

\footnotetext{
7 Se decanta por hacer coincidir la homogeneidad con estos elementos reales y sociales C. Sснмітт, La dottrina della Costituzione, 1928, trad. it., Milano, 1984, 490, para quien la homogeneidad de los miembros de la Federación venía dada por "una afinidad sustancial, que da fundamento a un acuerdo concreto, efectivo, de los Estados miembros", y su sustancia podría "tener que ver con los diversos ámbitos de la vida humana, por cuanto podría haber «una homogeneidad nacional, religiosa, de civilización, social o de clase, o de otro tipo. El citado autor subraya en particular la prevalencia de "una afinidad nacional de la población» y «a la homogeneidad de la población se suma asimismo como un elemento ulterior de homogeneidad la afinidad del principio político (monarquía, aristocracia o democracia)". Véase asimismo R. SMEND, Costituzione e diritto costituzionale, 1928, trad. it., Milano, 1988, 186 ss. e 248 ss., que considera al Estado federal como un «sistema de integración estatal que engloba a los Estados miembros como objeto" (p. 249), advirtiendo que los Estados miembros «no son solamente objeto de integración, sino también y ante todo instrumentos de integración" (p. 188); así, deja de lado todas las teorías meramente jurídicas del Estado federal, afirmando: "de lo que se trata aquí es, en cambio, de hacer frente al problema referente a cómo puede ser comprendido, en tanto que realidad, este tipo particular de Estado con sus dos polos políticos, esto es, el del Estado central y el de los Estados miembros (p. 186).
} 
una pluralidad de niveles que concurran a definir un ordenamiento compuesto-solamente si la dimensión jurídica viene alimentada por una multiplicidad de factores pre o metajurídicos que consientan la comprensión unívoca y la realización uniforme de las prescripciones.

La ciencia del Derecho constitucional sabe que no basta la presencia de un Carta que prescriba la democracia o los derechos fundamentales para que la primera se verifique en los procesos decisorios y los segundos sean garantizados y tutelados ante los poderes públicos; de la misma manera que, en el caso de ordenamientos complejos, no resulta suficiente la existencia de disposiciones que reconozcan las autonomías territoriales para que se produzca una auténtica descentralización de las funciones que lleve a adoptar las decisiones de la manera "más abierta y más próxima posible al ciudadano». En efecto, siempre será necesario que las formulaciones jurídicas vayan acompañadas de las correspondientes realidad socio-económica y dimensión espiritual, de modo tal que expresen aquellos presupuestos del ordenamiento que permitan a este último gozar de un cierto grado de efectividad, lo cual es condición esencial de su ser "deber-ser», esto es, de ser ordenamiento.

Desde este punto de vista, también asumen un significado las expresiones utilizadas en el preámbulo de la parte I de la Constitución y, tal vez, todavía más las declaraciones del otro preámbulo europeo, el que encabeza la parte II. En dichas expresiones se contienen, efectivamente, no sólo los mismos "valores" del principio de homogeneidad", sino asimismo el reclama "a la herencia cultural, religiosa y humanística de Europa", a partir de la cual se habrían desarrollado "los valores universales de los derechos inviolables e inalienables de la persona humana, la democracia, la igualdad, la libertad y el Estado de Derecho", poniendo de manifiesto así la estrecha conexión existente entre realidad y herencia europea ${ }^{9}$.

Todo esto, sin embargo, no autoriza en absoluto para considerar la homogeneidad a la que hace referencia el principio incluido en la Constitución europea (y ya antes en el Tratado de la Unión) como si se tratara de un canon de tipo sociológico; por tanto, aquélla no puede ser confundida con aquellos elementos (prejurídicos) que realizan una ho-

8 Significativo se revela en tal sentido el apartado 2 del Preámbulo de la Carta ( «la Unión está fundada sobre los valores indivisibles y universales de la dignidad humana, la libertad, la igualdad y la solidaridad, y se basa en los principios de la democracia y el Estado de Derecho»).

9 Apartado 1 del Preámbulo de la parte I del Tratado constitucional. 
mogeneidad socio-económica, ya que con ello se produciría un retroceso de la norma a la realidad, una vez más injustificada. En efecto, la Constitución europea asume en el ordenamiento elementos de homogeneidad, no tanto a efectos de una ponderación real en la que la consecuencia jurídica se basaría en la correspondencia o no con comportamientos sociales como ocurre en el caso de las de las cláusulas generales, sino con relación a una ponderación jurídica que puede afectar tanto al ordenamiento de la Unión como al de los Estados miembros, ya sea a su estructura organizativa ya sea al ejercicio de las respectivas funciones.

Dicho en otros términos, la homogeneidad no es un producto real, ligado a las acciones y a los comportamientos materiales de los sujetos que actúan en un determinado contexto, sino un principio jurídico que imprime un modo de ser al ordenamiento central y a los ordenamientos parciales, haciéndolos compatibles en un ordenamiento general.

Por lo demás, solamente partiendo de un enfoque jurídico de la homogeneidad resulta posible comprender cómo la realidad existencial de una serie de países de la ampliación, todavía no totalmente adaptados a determinados principios, que concurren a definir la homogeneidad, no haya sido un obstáculo a su ingreso en la Unión; más aún, se explicaría asimismo la previsión en el principio de homogeneidad de una parte programática, así como la afirmación de que "la Unión dispone de un marco institucional que tiene como finalidad promover sus valores" (artículo l-19.1 del Tratado constitucional).

\section{3. "HOMOGENEIDAD» Y CONSTITUCIÓN: CARÁCTER DEL PRINCIPIO Y LÍMITES A LA REFORMA DE LOS TRATADOS}

Si se atiende, por un lado, a la formulación positiva y, por otro, al régimen jurídico del principio de homogeneidad, resulta evidente el carácter no solamente constitucional, sino de "principio fundamental» de la misma Constitución que dicho principio reviste. La expresión utilizada en ambos textos objeto de análisis es siempre "la Unión se fundamenta...", atribuyendo con ello a los principios y/o a los valores en ellos indicados una posición diferenciada respecto al núcleo de los otros principios consagrados asimismo en el texto de la Constitución, y esta peculiar posición derivaría no tanto y simplemente de la formulación efectuada, cuanto de la circunstancia de que los elementos del principio de homogeneidad desempeñan una función particular en el plano de la interpretación constitucional del Derecho europeo, actuando en una doble dirección: ante todo, si en el texto de la Constitución o 
en la legislación europea han recibido un ulterior desarrollo, dichos elementos se convierten en los cánones hermenéuticos de referencia para resolver antinomias y colmar lagunas que se manifiesten en la aplicación de las normas; en segundo lugar, constituyen —en la parte en la que no resulten completamente disciplinados en el ordenamientopara el legislador europeo el cumplimiento de un deber, quedando éste obligado a regular institutos y a adopar normas de modo tal que efectúe un adecuado desarrollo de esos principios. Una obligación, esta última, que en el sistema europeo viene reforzada por la posibilidad de que el Tribunal de Justicia efectúe un control exclusivo de la legitimidad de los actos legislativos europeos a la luz de la Constitución ${ }^{10}$.

En síntesis, puede decirse que la homogeneidad constituye la compilación de los principios que permiten identificar a la "identidad" ${ }^{11} \mathrm{o}$ - si se me permite la expresión- la "forma de Estado" de la Unión, desde el momento en que "trazan los criterios esenciales relativos a las

10 Véase, a este respecto, el art. III-365 del Tratado constitucional, a tenor del cual: «1. El Tribunal de Justicia de la Unión Europea controlará la legalidad de las leyes y leyes marco europeas, de los actos del Consejo, de la Comisión y del Banco Central Europeo que no sean recomendaciones o dictámenes, así como de los actos del Parlamento Europeo y del Consejo Europeo destinados a producir efectos jurídicos frente a terceros. Controlará también la legalidad de los actos de los órganos u organismos de la Unión destinados a producir efectos jurídicos frente a terceros. 2. A efectos del apartado 1, el Tribunal de Justicia de la Unión Europea será competente para pronunciarse sobre los recursos por incompetencia, vicios sustanciales de forma, violación de la Constitución o de cualquier norma jurídica relativa a su ejecución, o desviación de poder, interpuestos por un Estado miembro, el Parlamento Europeo, el Consejo o la Comisión»; véase asimismo el art. III-369 del Tratado constitucional, a tenor del cual «El Tribunal de Justicia de la Unión Europea será competente para pronunciarse, con carácter prejudicial, sobre: a) la interpretación de la Constitución; b) la validez e interpretación de los actos adoptados por las instituciones, órganos u organismos de la Unión".

11 A ella se hace referencia en su preámbulo el Tratado de la Unión Europea, cuando - con el fin dar fundamento a la política exterior y de seguridad común, "que incluya la definición progresiva de una política de defensa común que podría conducir a una defensa común»- afirma: "reforzando así la identidad y la independencia europeas con el fin de fomentar la paz, la seguridad y el progreso en Europa y en el mundo" (sobre la cuestión de la identidad de Europa, véase F. CHABOD, Storia dell'idea d'Europa, 1961, trad. it., Roma-Bari, 2001; H. MIKKELI, Europa. Storia di un'idea e di un'identità, trad. it., Bologna, 2002; con un planteamiento de tipo social de la identidad europea, véase H. WALKENHORST, Europäischer Integrationsprozeß und europäische Identität, Baden-Baden, 1999; bajo una perspectiva más estrictamente constitucional, véase A. MANZELLA, L'identità costituzionale dell'Unione europea, en Studi in onore di Leopoldo Elia, Milano, 1999, 923 ss.). 
relaciones de la estructura organizativa con los otros elementos del ordenamiento" ${ }^{12}$. En tal sentido, "los valores de la dignidad humana, de la libertad, de la democracia, de la igualdad, del Estado de Derecho y del respeto de los derechos humanos" dan soporte a prescripciones materiales de la Constitución y poseen, tanto un contenido institucional y organizativo como un contenido apto para dar vida a un ordenamiento material. Por ello mismo figuran en una relación inmediata con los objetivos de la Unión, así como con los procesos decisorios internos de la Unión y con las reglas de reparto de competencias.

Dicho lo cual, antes de entrar a considerar estos últimos aspectos, parece necesario ponderar dos perfiles: el primero tienen que ver con el vínculo que crea la homogeneidad en el Derecho constitucional europeo, mientras el segundo afecta a la relación del principio de homogeneidad con la cuestión de la soberanía.

A este respecto, debe partirse de la consideración según la cual el principio aquí considerado viene expresado en disposiciones de la Constitución europea, que ha sido adoptada conforme a un procedimiento de Derecho internacional para la conclusión (y la ejecución) de un tratado. El mismo tratado prevé el procedimiento de modificación de la Constitución (artículo IV-443 del Tratado constitucional - Procedimiento de revisión ordinario) que sustancialmente consiste siempre asimismo en la regla en el Derecho internacional (apartado 3, párrafo 2: Las modificaciones entrarán en vigor después de haber sido ratificadas por todos los Estados miembros de conformidad con sus respectivas normas constitucionales) ${ }^{13}$, por más que, sobre la base de la experien-

12 Así, con relación a los cuatro principios fundamentales (democrático - personalista - laboral o social - pluralista) de la Constitución italiana individualizados por C. MoRTATI, Istituzioni di diritto pubblico, Padova, 1975, I, 9a ed., 148 ss.; los elementos del principio de homogeneidad — siguiendo el lenguaje utilizado por la doctrina alemana- pueden ser considerados como los Bauprinzipien der Verfassung (véase A. MERKL, Die Baugesetze der österreichischen Verfassungsrecht, en Die Republik Österreich, coord. por H.R. Klecatsky, Wien, 1968, 77 ss.) o los Strukturprinzipien eines Staates (véase K. STERN, Das Staatsrecht der Bundesrepublik Deutschland, 2. Aufl, München, 1984, I, 551 ss.) que constituyen [el marco constitucional de gobernabilidad] die für diesen maßgeblichen Leitgrundsätze seines Aufbaus, die gestaltgebenden Festlegungen seiner Staatlichkeit, kurz: die leitenden verfassungsrechtlichen Prinzipien, die der Staatsorganisation das Gepräge geben, the constitutional framework of government (p. 552).

${ }^{13}$ El poder de iniciativa para la revisión de la Constitución está atribuido, además de al "gobierno de cualquier Estado miembro", al Parlamento Europeo o la Comisión, que pueden someter al Consejo proyectos tendentes a modificar el Tratado que establece una Constitución para Europa. Los proyectos de modificación deben ser

(C) UNED. Revista de Derecho Político 
cia vivida, se prevea la posibilidad de convocar una "convención», a iniciativa del Presidente del Consejo Europeo, "si el Consejo Europeo, previa consulta al Parlamento Europeo y a la Comisión, adopta por mayoría simple una decisión favorable al examen de las modificaciones propuestas" (apartado 2, párrafo 1) ${ }^{14}$.

Ahora bien, el Tratado no prevé, en ninguna de sus normas o principios, la exclusión del procedimiento de revisión. Se puede decir que formalmente no existen límites a la revisión de los tratados. Una conclusión que seguramente resulta coherente con la circunstancia de que - del mismo modo que sucede en Derecho internacional- no subsisten vínculos que nazcan de un tratado que no puedan ser disueltos, en algunos casos incluso de manera unilateral. $Y$ es que también en el caso de los tratados que han dado vida al proceso de integración europea una constante ha sido la consideración de los Estados como "los señores de los tratados»"

transmitidos por el Consejo al Consejo Europeo, y notificados a los Parlamentos nacionales.

${ }^{14}$ La "Convención (estaría) compuesta por representantes de los Parlamentos nacionales, de los Jefes de Estado o de Gobierno de los Estados miembros, del Parlamento Europeo y de la Comisión" y, "cuando se trate de modificaciones institucionales en el ámbito monetario, se consultará también al Banco Central Europeo». Repárese en que «El Consejo Europeo podrá decidir por mayoría simple, previa aprobación del Parlamento Europeo, no convocar una Convención cuando la importancia de las modificaciones no lo justifique. En este último caso, el Consejo Europeo establecerá un mandato para una Conferencia de los representantes de los Gobiernos de los Estados miembros». Además, la Convención tendrá como cometido examinar los proyectos de revisión y adoptar por consenso una recomendación a una Conferencia de los representantes de los Gobiernos de los Estados miembros, la cual es convocada por el Presidente del Consejo con el fin de que se aprueben de común acuerdo las modificaciones del Tratado, que para entrar en vigor deberán haber sido ratificadas por todos los Estados miembros de conformidad con sus respectivas normas constitucionales. Finalmente, en caso de que los procedimientos constitucionales de los Estados miembros no tengan todos ellos una conclusión favorable, se prevé que, transcurrido un plazo de dos años desde la firma del Tratado por el que se modifica el Tratado por el que se establece una Constitución para Europa, si «las cuatro quintas partes de los Estados miembros lo han ratificado y uno o varios Estados miembros han encontrado dificultades para proceder a dicha ratificación, el Consejo Europeo examinará la cuestión». (apdo. 4). De esta disposición se desprende claramente que si dicha proporción no llega a alcanzarse, el procedimiento de modificación se verá bloqueado, sin que sean previsibles las decisiones susceptibles de ser adoptadas por el Consejo Europeo respecto a la ratificación fallida por parte de un o más Estados miembros.

${ }_{15}$ Véase H.P. IPSEN, Europäisches Gemeinschaftsrecht, Tübingen, 1972, 101 y 211, el cual subraya que «die Mitgliedstaaten haben damit als Subjekte des Völke- 
Sin embargo, una aproximación de este tipo se perfilaba, ya desde la aprobación del Tratado de Maastricht, como insuficiente para explicar el vínculo que los Estados contrayentes han concluido, dando vida a un proceso creciente de integración. No debe olvidarse, en efecto, que los Tratados mediante los que se creó la Unión Europea y, con mayor motivo, el que proveerá a dotarla de una Constitución, se diferencian sensiblemente de los demás tipos de tratados internacionales, por cuanto no se limitan a regular relaciones entre los Estados, sino que dan vida a una entidad supranacional que, si en el pasado (remoto) tuvieron un carácter funcional, en la medida en que apuntaba a la simple creación de un mercado común, ahora - como demostraría el propio principio de homogeneidad- ha asumido un carácter estructural y, además, caracterizado por la duración ilimitada del propio tratado (artículo IV-446 del Tratado constitucional) ${ }^{16}$.

Aunque no sea posible afirmar cuándo se habría realizado una mutación del carácter de la entidad supranacional (o, si se prefiere, que no ha sido configurada así desde el origen), puede en cambio sostenerse que, una vez instituida la Unión, cesa el papel constitutivo de los Estados miembros y la Unión opera a través de las disposiciones de su Constitución, para cuya eficacia se hace Ilamamiento, junto a las Instituciones, también a los Estados miembros. Pero sus acciones, en este caso, representarán la explicación de las competencias reconocidas por el Derecho europeo (rectius: por la Constitución) y ya no serán más el ejercicio de los poderes de Derecho internacional de los Estados miembros.

La misma aplicación del Derecho europeo no se somete a la aplicación de las reglas generales del Derecho internacional, sino a las propias del ordenamiento europeo ${ }^{17}$, incluso en el caso de que las deliberaciones del Consejo deban ser adoptadas por unanimidad en lugar de por mayoría. En efecto, como ha sido observado de manera autorizada,

rrechts und als Vertragsstaaten im Sinne des Völkerrechts gehandelt und sind folglich grundsätzlich den allgemeinen Regeln des Völkerrechts unterstellt».

${ }^{16}$ Es importante no infravalorar el significado de la disposición que afirma: «EI presente Tratado se celebra por un período de tiempo ilimitado" (art. IV-446), siendo ésta una característica esencial de la Unión que viene a indicar el carácter permanente del ordenamiento europeo, lo que difiere de cualquier reglamentación transitoria, y confiere al acto fundador, más allá de la forma jurídica del Tratado de Derecho internacional, una relevancia constitucional $y$, más específicamente, lo configura como un acto del poder constituyente.

17 Véase D. EdWARD, Direct Effect - Myth, Mess or Mystery, en Dir. Un. eu., 2002, 215 ss.

(C) UNED. Revista de Derecho Político 
"aun cuando las deliberaciones federales vengan formadas por la deliberación unánime de todos los miembros (...) y ninguno pueda quedar vencido como resultado de los votos, existe una diferencia esencial entre una deliberación federal y la deliberación unánime de una conferencia internacional, ya que la deliberación federal no requiere ninguna ratificación especial por parte de los Estados a título particular, quedando más bien cada Estado miembro constitucionalmente (...) vinculado de modo directo" ${ }^{18}$.

Esto explica asimismo por qué a los Estados miembros, que pese a todo no han perdido su capacidad (rectius: subjetividad) de Derecho internacional, no se les permite que puedan reaccionar respecto a los actos europeos según los principios del Derecho internacional, sino solamente en las formas y en los términos previstos por la Constitución ${ }^{19}$.

Esta circunstancia posee una multiplicidad de consecuencias: por ejemplo, con respecto a la cuestión del derecho de retirada de los Estados miembros de la Unión. Una cuestión, ésta, ampliamente debatida - asimismo y sobre todo en el caso de Austria- y que parece ahora haber encontrado una respuesta, conforme a lo que se desprende sistemáticamente de la Constitución en el artículo I-60. En efecto, ya hace tiempo que la doctrina más autorizada había puesto de relieve que en el caso de los Tratados europeos no podía concederse a los Estados miembros a título particular un verdadero y propio derecho de retirada, sobre la base de las reglas generales del Derecho internacional, incluso según los cánones de la cláusula rebus sic stantibus, por cuanto semejante modo de proceder habría significado una sustracción a las obligaciones específicamente asumidas ${ }^{20}$. La misma disposición de la Constitución que ahora regula la retirada prevé que ésta no se produzca mediante un acto unilateral, sino sobre la base de un acuerdo negociado entre la Unión y el Estado que pretenda retirarse, y el acuerdo define "la forma de su retirada, teniendo en cuenta el marco de sus re-

18 C. SCHMITT, La dottrina della Costituzione, cit., 502.

19 Véase, a este respecto, el art. III-375 del Tratado constitucional, según el cual: "2. Los Estados miembros se comprometen a no someter las controversias relativas a la interpretación o aplicación de la Constitución a un procedimiento de solución distinto de los establecidos en la misma. 3. El Tribunal de Justicia será competente para pronunciarse sobre cualquier controversia entre Estados miembros relacionada con el objeto de la Constitución, si dicha controversia se le somete en virtud de un compromiso".

20 Véase H.P. IPSEN, Europäisches Gemeinschaftsrecht, cit., 100.

21 Una disposición sobre la retirada de los Estados miembros es muy rara en las constituciones federales (un ejemplo, por lo demás carente de significación, viene 
laciones futuras con la Unión» ${ }^{21}$. Además, la propia Constitución no cesa automáticamente de ser aplicable con la notificación de la voluntad de retirada por parte del Estado miembro, sino que la limitación de su eficacia queda demorada a la entrada en vigor del acuerdo de retirada o, en su defecto dos años después de la notificación de la voluntad de retirada, quedando siempre a salvo la posibilidad de que el Consejo Europeo, de acuerdo con el Estado miembro interesado, decida por unanimidad prorrogar dicho plazo 22 .

ofrecido por la Constitución de la antigua URSS, en la cual dicha cláusula no tenía valor alguno, como consecuencia de la falta de normas de desarrollo), pero la previsión del Tratado que adopta una Constitución para Europa, en cambio, parece más bien asimilarse al trasfondo de la polémica canadiense en torno a la secesión de Quebec con el referéndum de 30 de octubre de 1995, la decisión del Tribunal Supremo de 20 de agosto de 1998 y la legislación federal (Clarity Act) y provincial (Quebec Act) del año 2000. En particular, la decisión del Tribunal Supremo (Renvoi Relatif à la Sécession du Quebec [1998] 2 R.C.S., 217-297) había puesto de relieve que un eventual acto de secesión unilateral habría estado injustificado desde el punto de vista constitucional, pese a haberse basado en la existencia de un referéndum favorable, por cuanto el principio democrático no representaba el único basamento del sistema canadiense, y el acto unilateral habría representado una violación de otros principios igualmente importantes, "namely, the rule of law, federalism and minority rights"; como, por lo demás, habría resultado asimismo inaceptable desde el punto de vista del Derecho internacional, por cuanto, aun prescindiendo de la existencia en el plano internacional de un "Quebec people», el principio de autodeterminación de los pueblos sólo es ejercitable en presencia de un "people suffering oppressive colonial subjugation», condición — subraya el Tribunal- "manifestly inapplicable in Quebec under existing circumstances». Sin embargo, el Tribunal preveía que, en donde se hubiere manifestado mediante un referéndum la voluntad de secesión de la provincia, los otros entes integrados en la Federación habría debido negociar con Quebec, y dicha obligación sí habría formado parte de los principios de la Constitución canadiense (véase P.M. DAwson, Reflections on the Opinion of the Supreme Court of Canada in the Quebec Secession Reference, en National Journal of Constitutional Law, 1999-2000, vol. 11, 5 ss.; W.J. NeWMAN, Réflexions sur la porteé ventable des principes constitutionnels dans l'interprétation et l'application de la Constitution du Canada, ivi, 2001-2002, vol. 13, 117 ss.; P.H. RusselL, Constitutional Odyssey. Can Canadians Become a Sovereign People?, Toronto-Buffalo-London, 2004, $3^{\mathrm{a}}$ ed., 228 ss.). Más allá de la circunstancia de que la Corte no haya llevado sus razonamientos hasta las últimas consecuencias, por lo que su decisión deja sin resolver una serie compleja de problemas constitucionales, debe destacarse la circunstancia según la cual, en sistemas con una estructura federal, la cuestión de la retirada de un Estado miembro se considera, no un acto de fuerza unilateral, sino una forma de reforma de la Constitución federal. Esto parece ser lo asumido y codificado en el artículo art. I-60 del Tratado constitucional.

${ }^{22}$ Esta disposición reviste un carácter peculiar para la interpretación de la Constitución europea y para definir, tanto la posición de la Unión, como la de los Estados 
Esta configuración de las relaciones entre Estados miembros y Unión en el marco que se está delimitando no puede quedar desprovista de efectos respecto a las disposiciones de la propia Constitución. En particular, si bien es cierto que los Estados miembros pueden actuar únicamente en el marco normativo de la Constitución, ésta viene a configurarse no sólo como el acto que fundamenta su participación, sino sobre todo como el contenido de la misma participación. En esta lógica, también el poder de revisión de los tratados asume un valor diverso en comparación con la negociación y estipulación de un mero acuerdo internacional, siquiera sea en términos de su celebración solemne. En efecto, prescindiendo de la revisión simplificada, el procedimiento ordinario del artículo IV-443 es sólo el instrumento para adecuar el contenido de la Constitución en el tiempo, quedando por ello mismo vinculado a la normativa existente, no sólo desde el punto de vista procedimental, sino asimismo en cuanto a algunos contenidos normativos.

Desde este punto de vista, parece poder concluirse que la formulación del principio de homogeneidad, al indicar los elementos que caracterizan la forma de la Unión, reviste un cierto grado de rigidez que afecta asimismo a las relaciones entre la Unión y los Estados miembros en materia de reforma de la Constitución. En efecto, la modificación de los principios que expresan la homogeneidad incidirá en la identidad de la misma Unión y determinaría propiamente una verdadera ruptura constitucional.

miembros, estando estrechamente relacionada con la previsión más arriba citada acerca de la duración ilimitada de la Unión. En efecto, si ésta tiene, por declaración expresa, un carácter permanente, con su adhesión los Estados miembros se sitúan en el ámbito de un sistema constitucional que no contempla derecho alguno de secesión unilateral; y la afirmación según la cual la Unión es pese a todo el fruto de un acuerdo entre Estados comporta en el orden europeo que éstos mantienen su efectiva subjetividad política, la cual comprende asimismo la posibilidad para los Estados miembros el poder de decidir sobre su participación y permanencia en la Unión; sobre este punto, véase asimismo la posición expresada por el Tribunal Constitucional español (Declaración n. ${ }^{\circ}$ 1/2004, de 13 de diciembre de 2004, en www.tribunalconstitucional.es, así como en www.associazionedeicostituzionalisti.it/cronache/estero/Spagna_europa/index.html con el comentario de A. SCHILLACI, Il Tribunale Costituzionale spagnolo e la Costituzione europea). 


\section{LA HOMOGENEIDAD Y LA CUESTIÓN DE LA SOBERANÍA: NETA DISTINCIÓN DE AMBAS PROBLEMÁTICAS}

En lo que atañe a la cuestión de la soberanía, ésta no se encuentra directamente conectada con el principio de homogeneidad ${ }^{23}$. Quienes entienden que existe dicha conexión parten del presupuesto de que la homogeneidad -entendida en sentido sustancial (como afinidad nacional de la población, o como afinidad del principio político: la democracia) - impide en la Federación salvar la antinomia determinada por la «existencia como un todo de la federación y por la existencia particular de los miembros de la federación»; y, por tanto, gracias a la homogeneidad, el denominado "dualismo de existencia política», derivado del entramado de cohesión federal y de unidad política, con la subsistencia de una multiplicidad de Estados, esto es un pluralismo de unidades políticas particulares, puede cobrar vida a través de un equilibrio que permite a la Federación continuar existiendo, en cuanto tal ${ }^{24}$.

En razón de lo anterior se afirma que «pertenece a la esencia de la federación el hecho de que la cuestión de la soberanía permanezca siempre abierta entre federación y Estados miembros, hasta que la federación como tal exista junto a los Estados miembros como tales", dado que «ni la federación respecto al Estado miembro, ni el Estado miembro respecto a la federación, desempeñan el papel de soberano" ${ }^{25}$.

Sobre la base de esta enseñanza, la posición mayoritariamente defendida para explicar la evolución del ordenamiento europeo ha sido la tesis según la cual quien se atiene a los aspectos positivos del proceso de integración europea, puede renunciar a responder a la cuestión de la soberanía, "denn angesichts der Realität der Vergemeinschaftung ist sie keine Frage mehn ${ }^{26}$.

${ }^{23}$ En sentido diverso, C. SchmitT, La dottrina della Costituzione, cit., 483 ss., 493 s..

24 Véase C. Schmitt, La dottrina della Costituzione, cit., 486.

${ }^{25}$ C. SchmitT, La dottrina della Costituzione, cit., 486 e 494. Repárese en que la acepción con la que Schmitt se refiere al término "federación" supera el esquema lógica de la distinción entre Confederación de Estados y Estado federal (véase $p$. 477), de lo que se extrae en este punto una enseñanza particularmente significativa, por cuanto propicia el adecuado encuadre asimismo de la expresión Staatenverbund, utilizado por el Tribunal Constitucional Federal alemán en la Maastricht-Urteil.

26 H.P. IPSEN, Europäisches Gemeinschaftsrecht, cit., 227 ss., el cual prosigue afirmando: "Darin läge dann der Beitrag der Gemeinschaftsrechtslehre zur Souveränitätskritik» (p. 233). 
No es ésta la sede para reexaminar los términos en los cuales los poderes soberanos estarían divididos o compartidos entre la Unión Europea y los Estados miembros: si -por ejemplo- la parte más relevante del "poder exterior" habría quedado en manos de lo Estados o ha sido transferido a la Unión; si tendría más peso, a estos efectos y en la realidad actual, la "política comercial común», o la "política de seguridad y de defensa común ${ }^{27}$.

Con la suscripción del Tratado por el que se establece una Constitución para Europa, la investigación sobre este punto, con objeto de clarificar la naturaleza jurídica de la Unión Europea y de su propio ordenamiento, ha dado lugar a una compleja e interesante discusión, desde el momento en que los términos dentro de los cuales se desenvuelven las mismas políticas intergubernamentales han acabado resultando modificadas respecto a su precedente formulación en los tratados (Maastricht, Ámsterdam, Niza).

Por otra parte, si bien resulta comprensible que la cuestión de la soberanía pueda seguir siendo evocada, es necesario aclarar que su explicación no pasa por la presencia del principio de homogeneidad, que es algo profundamente diverso respecto a la eventual "homogeneidad" de hecho que propicia que los Estados miembros puedan soportar más fácilmente las limitaciones de la soberanía que derivan del proceso de integración europea. En efecto, el principio de homogeneidad no se limita a constatar las afinidades existentes entre las diversas partes de la Unión, sino que posee un contenido normativo que impone, tanto a la Unión como a los Estados miembros, una caracterización de sus respectivos ordenamientos según determinados elementos, positivamente definidos por la Constitución.

Dicho en otros términos, la homogeneidad no es un presupuesto de hecho (existencial) que deje abierta la cuestión de la soberanía europea, sino una conformación del modo de ser del sistema europeo, que actúa positivamente y reclama una contínua actividad de concreción por parte de las Instituciones y de los Estados miembros. La homogeneidad es jurídicamente un producto de la Constitución, y como tal requiere ser tratado.

Desde este punto de vista, la capacidad del principio de homogeneidad para vincular a (la constitución de) los Estados miembros, deri-

27 Sobre este punto, véase F. ChALTIEL, La Souveraineté de l'État et I'Union Européenne, l'exemple français. Recherches sur la Souveraineté de l'État membre, Paris, 2000, 259 ss. y 391 ss.; así como N. McCoRMICK, La sovranità in discussione, trad. it., Bologna, 2003. 
va del ordenamiento europeo y se basa en el mismo fundamento de éste, o sea, en el compromiso asumido mediante la suscripción de los tratados de semejante sujeción al Derecho europeo y a la jurisdicción del Tribunal de Justicia.

\section{LA HOMOGENEIDAD COMO SUJECIÓN A UN MISMO ORDENAMIENTO CUYOS PRINCIPIOS SON COMPARTIDOS POR LOS ORDENAMIENTOS PARCIALES: LOS PELIGROS DE LA UNIFICACIÓN $Y$ LA IDENTIDAD DE LOS ESTADOS MIEMBROS}

La disposición constitucional que enuncia el principio de homogeneidad tras haber dado cuenta de los valores en los que se fundamenta la Unión, afirma: "Estos valores son comunes a los Estados miembros.... ${ }^{28}$.

La interpretación que pueda darse a esta interpretación es, en sí, bastante compleja. La expresión se encuentra asimismo en el artículo 6.1 TUE ("... principios que son comunes a los Estados miembros») y deriva históricamente de la codificación de los resultados alcanzados por el ordenamiento europeo merced a la jurisprudencia del Tribunal de Justicia. En el sistema del Tratado de la Unión, por tanto, la disposición tenía un carácter de reconocimiento de los elementos jurídicos de los ordenamientos constitucionales de los Estados miembros, lo que conducía a tener por formulada en la disposición del Tratado sólo una homogeneidad horizontal, aunque la previsión del artículo 7 TUE pudiera dejar intuir desarrollos diversos.

En la disposición de la Constitución, la interpretación susceptible de efectuarse respecto tal inciso se perfila, desde el punto de vista literal, un tanto diversa. En efecto, la norma no engloba sencillamente los elementos comunes de los Estados miembros, sino que se los impone (la denominada homogeneidad vertical), en el sentido de que en virtud de la Constitución europea las constituciones de los ordenamientos parciales deben asegurar el respeto de la dignidad humana, la libertad, la democracia, la igualdad, el Estado de Derecho y el respeto de los derechos humanos, incluidos los derechos de las personas pertenecientes a una minoría.

Muy probablemente nos encontramos en presencia de una tendencia de tipo federal que confiere un carácter de Derecho público a las re-

28 «...en una sociedad caracterizada por el pluralismo, la no discriminación, la tolerancia, la justicia, la solidaridad y la igualdad entre mujeres y hombres». 
laciones entre Unión y Estados miembros, y que permite a la primera supervisar los ordenamientos de los Estados miembros ${ }^{29}$. En tal sentido, la Constitución europea se reconstruye como el ordenamiento general dentro del cual subsiste la posibilidad para los ordenamientos (territoriales) parciales de moverse e interactuar, mientras que su comparación vendría dada por los elementos que constituyen el principio de homogeneidad.

Pero el sistema puede dar lugar a desarrollos inéditos a cuya realización puede contribuir el principio de homogeneidad. Como es sabido, la "homogeneidad" se distingue de la "uniformidad", y lo específico de un ordenamiento complejo articulado en varios niveles viene dado por la capacidad de hacer convivir una multiplicidad en el seno de un único marco. Ello no obstante, los procesos de homogeneización son, en cierta medida, procesos de unificación que amenazan la sustancia federal, sobre la base de la cual algunas decisiones son adoptadas a nivel europeo y otras a nivel descentralizado de Estado miembro.

Si sólo se tratase de compartir determinados "principios" o "valores", no podría atribuirse a la homogeneidad un cometido aglutinador, puesto que verificada su presencia en las constituciones de los Estados miembros y su respeto en la praxis de las decisiones y de la actividad, nada más parece que pudiere pretender de aquéllos la Unión.

En realidad, parece evidente que la homogeneidad no es un principio estático, sino dinámico, que requiere día a día acciones coherentes con los elementos que han sido incluidos como fundamento de su definición por la Constitución europea. Por esta vía se genera una situación de tensión entre la multiplicidad y la complejidad de los Estados miembros y la univocidad a la que empujarían los componentes de la homogeneidad. En particular, si en el caso de los derechos y de las garantías la Ciencia del Derecho constitucional ya hace tiempo que individualizó una posibilidad de regulación en la acción concurrente de los poderes con la aplicación del principio de una protección más extensa, no puede decirse otro tanto con relación a otros elementos. En efecto, en el caso de la "democracia" subsiste una competencia tal con el "principio federal», el cual debería gobernar la Unión, que podría llegar a hacer sucumbir dicho principio.

La cuestión no es nueva. Ya Carl Schmitt puso de manifiesto que "tanto la democracia como la federación se basan en el presupuesto de la homogeneidad" y, "si se forma una federación de Estados demo-

${ }^{29}$ Sobre este punto, véase el apartado siguiente. 
cráticos, la consecuencia necesaria es que la homogeneidad democrática confluya con la homogeneidad federal», pero en ello veía asimismo el peligro de llegar "a un tipo peculiar y autónomo de organización estatalı: el Estado federal sin fundamento federativo ${ }^{30}$. La afirmación según la cual "con el concepto democrático del poder constituyente de todo el pueblo queda abolido el fundamento federativo y, con ello, el carácter federal $»^{31}$, derivaría de la circunstancia según la cual el desarrollo del proceso de decisión democrática, representada por un único pueblo en el seno de un sistema progresivamente homogéneo, conduce a considerar irrelevante el lugar en el que la decisión misma sea adoptada.

La razón de este particular proceso evolutivo de tipo unificador, que puede derivar de la cohonestación del principio democrático con el principio federal, ha sido ampliamente experimentado en la historia de los Estados federales ${ }^{32}$, sin que la experiencia europea haya dejado de mostrar ya asimismo rasgos de este tipo. En los Estados federales, a medida que ha crecido la democracia, ha disminuido la autonomía de los Estados miembros ${ }^{33}$. El signo más evidente, pero no el único, de este proceso, ha sido la concentración de competencias en manos de la Federación, lo que ha conducido a un empobrecimiento de las legislaciones locales ${ }^{34}$. En Europa, el crecimiento desmesurado de las competencias de la Comunidad y la intromisión de los poderes de las Instituciones han sido vistos como una amenaza para la autonomía política de los Estados miembros, denunciada mediante la incompatibilidad de semejante acumulación de poder en un sistema con tan baja legitimidad democrática. Sin embargo, la apelación al déficit democrático de Europa, ampliamente denunciado, corría el riesgo de no revelarse un buen argumento en defensa de las prerrogativas de los Estados miem-

30 La dottrina della Costituzione, cit. 507, a esta expresión reconducía Schmitt los Estados Unidos de América y el Reich alemán de la Constitución de Weimar, excluyendo que se tratase de una federación, entendida como una nueva forma de Estado en la que se retomaban elementos de una precedente organización federal, pero en realidad se trataría de un Estado unitario, con un solo pueblo y con la abolición del carácter estatal de los Estados miembros, en donde la cuestión la cuestión de la soberanía se habría resuelto a favor de la sola soberanía del Estado central (508).

${ }^{31}$ C. SchMitT, La dottrina della Costituzione, cit. 508.

${ }^{32}$ Resulta emblemático a este respecto el análisis efectuado por K. HESSE, Der unitarische Bundesstaat, Karlsruhe, 1962.

${ }^{33}$ Véase R.A. DAHL, Quanto è democratica la Costituzione americana?, trad. it., Roma-Bari, 2003.

34 ... en el caso alemán, si acaso compensado con la participación en el procedimiento legislato federal de los Länder a través del Bundesrat. 
bros $^{35}$. Así, con el Tratado de Maastricht, ya con anterioridad a la formulación del principio de homogeneidad, la cuestión se traslada a un elemento diverso: el del respeto de la identidad nacional de los Estados miembros ${ }^{36}$.

A continuación, en el marco del principio de homogeneidad, se ha operado una comparación entre la identidad europea y la de los Estados miembros, con remisiones continuas asimismo a la cuestión de la soberanía ${ }^{37}$. En este ámbito, el hecho de que los principios (y los valores) de la homogeneidad se correspondan, tanto con la identidad europea como con la de los Estados miembros, ya no es relevante, estando Ilamada la identidad de estos últimos a desempeñar, desde el punto de vista sistemático, una función absolutamente diversa de la que corresponde al principio de homogeneidad. En efecto, al estar basada en los mismos elementos que la identidad de la Unión, la identidad de los Estados miembros sirve para delimitar la acción de ésta.

La cuestión resulta más clara en la formulación que del principio de identidad se efectúa en la Constitución europea, en donde se regulan las relaciones entre la Unión y los Estados miembros (artículo l-5.1 del Tratado constitucional). Aquí, efectivamente, una vez superados los elementos de la homogeneidad, se afirma que "la Unión respetará la igualdad de los Estados miembros ante la Constitución, así como su identidad nacional, inherente a las estructuras fundamentales políticas y constitucionales de éstos, también en lo referente a la autonomía local y regional. Respetará las funciones esenciales del Estado, especialmente las que tienen por objeto garantizar su integridad territorial, mantener el orden público y salvaguardar la seguridad nacional».

Junto al principio de igualdad federal, a tenor del cual ningún Estado miembro puede tener una posición diferenciada más allá de los ca-

${ }^{35}$ Sobre este punto, véase M. KaUfMANN, Europäische Integration und Demokratieprinzip, Baden-Baden, 1997.

${ }^{36} \mathrm{Cfr}$. art. F pár. 1 TUE "La Unión respetará la identidad nacional de sus Estados miembros, cuyos sistemas de gobierno se basan en principios democráticos». La versión que asume este principio en la formulación de Ámsterdam, con la introducción del principio de homogeneidad (art. 6.1), es sensiblemente diversa, por cuanto el elemento democrático queda integrado en la homogeneidad, mientras el art. 6.3 se limita a declarar que «La Unión respetará la identidad nacional de sus Estados miembros".

${ }^{37}$ El tema de la identidad había sido suscitado sobre todo por la República federal alemana, con relación a la incidencia que el proceso de integración ejercía sobre el federalismo interno, con la pérdida progresiva de "estatalidad" por parte de los Länder. 
sos previstos por la Constitución, resulta evidente que el reclamo a la «identidad nacional» no reviste un carácter material o sociológico, esto es, no representa una referencia a la cultura, a la lengua y, en algunos casos a la religión, sino que posee un valor estrictamente jurídico ${ }^{38}$. Esta aclaración, que pone fin a los equívocos surgidos en torno al tema de la "identidad" en la interpretación del Tratado de la Unión Europea, se basa en dos consideraciones distintas.

En primer lugar, la diversidad de la cultura, de la lengua y de la religión son objeto de una específica y adecuada tutela en la Constitución europea. Ésta, efectivamente, afirma, tanto en la primera parte como en la segunda, la valoración de los elementos de diferenciación nacional ${ }^{39}$, y en la tercera parte atribuye la "cultura" a la competencia de los Estados miembros, en cuyo ámbito la Unión puede simplemente "decidir llevar a cabo una acción de apoyo, de coordinación o de complemento", estando ya presentes bajo esta forma, tanto la valoración "de las diversidades nacionales y regionales" como asimismo un elemento - siquiera sea mínimo- de unificación ${ }^{40}$, de manera análoga a como se efectúa en el preámbulo de la Constitución europea, en donde se afirma que los pueblos de Europa, sin dejar de sentirse orgullosos de su identidad y de su historia nacional, están decididos a superar sus antiguas divisiones $y$, cada vez más estrechamente unidos, a forjar un destino

${ }^{38}$ Sobre el concepto de Nación, referida a sus elementos de tipo material y a las interferencias con el Estado y con el pueblo, véase V. CRISAfULLI - D. Nocilla, Nazione, Milano, 1977; véase asimismo E.J. HobSBAWM, Nazioni e nazionalismi dal 1780. Programma, mito, realtà, trad. it., Torino, 1991; E. GeLNER, Nazioni e nazionalismo, trad. it., Roma, 1992; H. U. WEHLER, Nazionalismo. Storia forme e conseguenze, trad. it., Torino, 2002; P GrILLI DI CORTONA, Stati nazioni e nazionalismi in Europa, Bologna, 2003.

39 Véase art. I-3 del Tratado constitucional "(La Unión) respetará la riqueza de su diversidad cultural y lingüística y velará por la conservación y el desarrollo del patrimonio cultural europeo»; y art. II-82 del Tratado constitucional: "La Unión respeta la diversidad cultural, religiosa y lingüística».

40 Véase art. III-280.1 del Tratado constitucional: "La Unión contribuirá al florecimiento de las culturas de los Estados miembros, dentro del respeto de su diversidad nacional y regional, poniendo de relieve al mismo tiempo el patrimonio cultural común". Véase asimismo par. 4: "La Unión tendrá en cuenta los aspectos culturales en la actuación que lleve a cabo en virtud de otras disposiciones de la Constitución, en particular a fin de respetar y fomentar la diversidad de sus culturas"; y el pár. 5: "Para contribuir a la consecución de los objetivos enunciados en el presente artículo: a) la ley o ley marco europea establecerá medidas de fomento, con exclusión de toda armonización de las disposiciones legales y reglamentarias de los Estados miembros. La ley o ley marco se adoptará previa consulta al Comité de las Regiones; b) el Consejo adoptará recomendaciones a propuesta de la Comisión». 
común, reclamando así la categoría que Renan sitúa como fundamento de la Nación ${ }^{41}$.

En segundo lugar, a favor de una acepción jurídica del principio de identidad jugaría la misma disposición que lo reclama, por cuanto, de un lado, remite a la estructura fundamental, política y constitucional, incluido el sistema de autonomías locales y regionales y, de otro, especifica el respeto de las "funciones esenciales del Estado". Un planteamiento, éste, que resultaba anticipado por un pasaje del preámbulo de la Carta de los derechos, en el cual los valores comunes están salvaguardados y desarrollados en el respeto, no sólo "de la diversidad de culturas y tradiciones de los pueblos de Europa», sino asimismo "de la identidad nacional de los Estados miembros y de la organización de sus poderes públicos a escala nacional, regional y local ${ }^{42}$.

La identidad a la que se refiere la Constitución europea es la identidad de los Estados miembros como institución, es decir, a su forma de Estado. De la formulación adoptada se colige con claridad que la salvaguarda de la identidad no plantea un tutela de existencia de los Estados miembros ${ }^{43} y$, en consecuencia, no resulta convincente la posición de quienes, con relación a la identidad de los Estados miembros, asume como obligación de la Unión la de no impulsar el proceso de integración hasta el punto de reducir a la nada "la condición jurídica y política de los Estados miembros ${ }^{44}$. En efecto, la garantía de la identidad de los Estados miembros opera en el sistema de garantía establecido por el ordenamiento europeo; o dicho en otros términos, su previsión serviría de bien poco o sería prácticamente inutilizable en caso de pretenderse una resolución de la decisión sobre la soberanía a favor de la Unión ${ }^{45}$.

En este sentido, el tema de la identidad no es una cuestión que afecte a la existencia de los Estados miembros, sino más propiamente a los elementos organizativos de su autonomía legislativa, administra-

41 Véase E. Renan, Che cos'è una Nazione?, 1882, trad. it., Roma, 1993.

42 Véase, del Tratado constitucional, parte II, preámbulo, frase 3.

43 ... la cual se basa en su soberanía y en la capacidad de ellos para mantenerla.

${ }^{44}$ A. BLECKMANN, Die Wahrung der "nationalen Identität" im Unions-Vertrag, en $J Z, 1997,265$.

45 Menos convincente aún resulta la tesis según la cual la norma pueda dar lugar a una Wesensgehaltgarantie (así, A. BLECKMANN, Die Wahrung der "nationalen Identität» im Unions-Vertrag, cit., 265), revelándose tal concepto particularmente versátil, por cuanto presupondría aspectos de la identidad susceptibles de cesión, junto a aspectos no cedibles, sin contar con que la Unión está llamada a respetar la identidad del Estado miembro en cuanto tal. 
tiva y judicial; debiendo estarse atentos, también en este caso, para no confundir la identidad con el entramado de las competencias estatales y con la posibilidad de mantenerlas, con respecto a la atracción ejercida por los poderes europeos ${ }^{46}$.

Más consistente se revela, con respecto a la problemática aquí considerada, la tesis que sustenta la identidad como expresión de la forma de Estado, considerándola, a la luz del proceso europeo, como estatalidad integrada ${ }^{47}$, superando de este modo los problemas emergentes relativos a la cuestión de la soberanía europea. Si acaso, lo que no parece aceptable de este planteamiento es el punto de llegada. Efectivamente, admitir que, por mor del proceso de integración europea, la obligación de respeto de la identidad se reduce a una simple toma en consideración (de la identidad), y no a su intangibilidad, significa de hecho conceder a la Unión, a través del ejercicio de sus competencias, un permiso para atacar progresivamente la identidad de los Estados miembros.

En verdad, si se repara en que la identidad de un Estado viene dada por los elementos que caracterizan su forma de Estado, el respeto a que viene obligada la Unión comporta el vínculo para esta última consistente en dejar que los Estados miembros tengan plena disponibilidad sobre todas las opciones inherentes a su modo de ser, tanto al presente como al futuro. De ahí el reclamo en la nueva formulación a la estructura fundamental, política y constitucional, incluido el sistema de autonomías locales y regionales, que obviamente afecta asimismo a los elementos considerados por el principio de homogeneidad y que vienen prescritos a los Estados miembros.

Definido de tal suerte el principio de identidad, éste resulta completado por la obligación impuesta a la Unión de respetar asimismo de respetar "las funciones esenciales del Estado, especialmente las que

46 Véase, al respecto, la afirmación contenida en la sentencia Maastricht del Tribunal Constitucional Federal alemán (BVerfGE, 89, 155 ss., trad. it., en Giur. cost., 1994, 677 ss.) según la cual, gracias a los principios de subsidiariedad y de proporcionalidad, "deberían ser salvaguardadas la identidad nacional y las atribuciones de los Estados miembros» (p. 709). En particular, el principio de proporcionalidad «puede limitar la intensidad de penetración de los actos comunitarios asimismo en función de la obligación establecida en el art. F, apartado 1 TUE; de tal suerte, dicho principio salvaguarda la identidad nacional de los Estados miembros y, con ellos, los cometidos y las funciones de sus parlamentos frente al exceso de normativa europea».

47 M. HILF, Europäische Union und nationale Identität der Mitgliedstaaten, en Gedächtnisschrift für Eberhard Grabitz, coord. por A. Randelzhofer, R. Scholz e D. Wilke, München, 1995, 157 ss. 
tienen por objeto garantizar su integridad territorial, mantener el orden público y salvaguardar la seguridad nacional».

En particular, a esta ulterior obligación, más allá de su especificación meramente ejemplificativa, debe atribuirse un significado sustancial y dinámico, por cuanto pretende asegurar la vitalidad de la identidad de los Estados miembros. Con ello se corresponden en el texto de la Constitución europea todas aquellas disposiciones que valoran las aportaciones de los órganos de los Estados miembros ${ }^{48}$, e incluso de sus ciudadanos ${ }^{4950}$.

${ }^{48}$ La previsión sobre el respeto de las funciones esenciales del Estado persigue, en sus trazos principales, poner en relación la participación de los parlamentos nacionales, sobre todo, con la materia de política de seguridad y justicia; véase art. I42.2 del Tratado constitucional ("Los Parlamentos nacionales podrán, en el marco del espacio de libertad, seguridad y justicia, participar en los mecanismos de evaluación establecidos en el artículo III-260. Estarán asociados al control político de Europol y a la evaluación de la actividad de Eurojust con arreglo a los artículos III-276 y III-273»); además de ello, se introduce alguna otra previsión sobre cuestión competencial, como el art. I-11.3 del Tratado constitucional («Las instituciones de la Unión aplicarán el principio de subsidiariedad de conformidad con el Protocolo sobre la aplicación de los principios de subsidiariedad y proporcionalidad. Los Parlamentos nacionales velarán por el respeto de dicho principio con arreglo al procedimiento establecido en el mencionado Protocolo") y el art. I-18.2 del Tratado constitucional ("La Comisión Europea, en el marco del procedimiento de control del principio de subsidiariedad mencionado en el apartado 3 del artículo I-11, indicará a los Parlamentos nacionales las propuestas que se basen en el presente artículon); finalmente, se subraya la participación de los parlamentos nacionales en procedimientos específicos, como en el caso de las nuevas peticiones de adhesión a la Unión (art. I-58.2 del Tratado constitucional) y de revisión de los tratados (art. IV-443 e 444 del Tratado constitucional).

49 No puede olvidarse, en este contexto, la nueva formulación del principio de proximidad introducido en el artículo relativo al principio de la democracia representativa (Art. I-46.3 del Tratado constitucional: «Todo ciudadano tiene derecho a participar en la vida democrática de la Unión. Las decisiones serán tomadas de la forma más abierta y próxima posible a los ciudadanos»).

${ }^{50}$ En materia de derechos, merecen asimismo una mención particular, en este contexto, las tradiciones constitucionales comunes, respecto de las cuales, además de retomarse lo dispuesto en el art. 6.2 TUE y retomarse lo consignado en el art. I-9.3 («Los derechos fundamentales que garantiza el Convenio Europeo para la Protección de los Derechos Humanos y de las Libertades Fundamentales y los que son fruto de las tradiciones constitucionales comunes a los Estados miembros forman parte del Derecho de la Unión como principios generales»), se prescribe en el art. II-112 del Tratado constitucional, relativo al Alcance e interpretación de los derechos y principios, que "En la medida en que la presente Carta reconozca derechos fundamentales resultantes de las tradiciones constitucionales comunes a los Estados miembros, dichos derechos se interpretarán en armonía con las citadas tradi- 


\section{HOMOGENEIDAD Y ORDENAMIENTO COMPLEJO: CONSTITUCIÓN EUROPEA Y CONSTITUCIÓN DE LOS ESTADOS MIEMBROS}

A partir del principio de homogeneidad, por ello mismo, se origina un entramado de relaciones entre la Unión y los Estados miembros, entre sus respectivas identidades, sus organizaciones, sus respectivas funciones y actos. La homogeneidad requiere que cada cual, la Unión y cada Estado miembro, organicen su propia forma jurídica de existencia. El acto que determina este efecto es la constitución.

A la luz de esta consideración, debe entonces ser evaluado el alcance y la función, para los Estados miembros, del principio de homogeneidad prevista por la Constitución europea.

Desde este punto de vista, cabe observar cómo, hasta ahora, incluso tras la vigencia del Tratado de la Unión, semejante cuestión no habría podido plantearse de forma objetiva: los tratados no son una constitución, la misma Unión se presentó de manera incierta, con una fisonomía problemática, la Comunidad Europea se resentía todavía de su origen como una asociación con una concreta finalidad; más aún, se ha llegado a decir que la Unión no es ni debe convertirse en un estado, no existe un pueblo europeo que pueda dar lugar a una constitución, y es impensable una constitución sin Estado. En otros términos, en cierto grado se ha negado la posibilidad formal, negándose asimismo en cierta medida la capacidad sustancial de la Unión (y de la Comunidad) para actuar de modo constitucional $y$, en un marco de este género, la homogeneidad no podía ser sino un trasunto de los principios de estructura común a los Estados miembros, deducidos de sus respectivas Constituciones.

Ahora bien, tras haber sido suscrito un texto constitucional y haberse afrontado asimismo algunas cuestiones históricas relativas a la política exterior y de seguridad común y a la política de seguridad y de defensa común, las discusiones planteadas por la doctrina acerca de la capacidad constitucional de la Unión pueden considerarse, cuando menos, ya no del todo apropiadas. La homogeneidad asume -como se ha dicho- un carácter vertical: ella no se limita a retomar, sino que prescribe asimismo la necesidad de dar carta de naturaleza a los elementos que, según la disposición constitucional, la caracterizan.

ciones" (pár. 4) y que "Se tendrán plenamente en cuenta las legislaciones y prácticas nacionales según lo especificado en la presente Carta» (pár. 6). 
Este punto de llegada implica algunas consecuencias sobre la función que desempeña el principio de homogeneidad. En primer lugar, si éste prescribe un determinado contenido, es también fuente de una garantía, ya que exige que sea el Estado miembro, y no la Unión, quien haga efectivo, en el ámbito de su jurisdicción, "el respeto de la dignidad humana, la libertad, la democracia, la igualdad, el Estado de Derecho y el respeto de los derechos humanos". En tal sentido, la homogeneidad designa una esfera reservada intangible por parte del ordenamiento europeo, en donde el comportamiento del Estado miembro está, sin embargo, prescrito, consistente en hacer propios los principios estructurales indicados y desarrollarlos en el ordenamiento y en la praxis habitual del Estado.

En este punto, obviamente, más allá de la relación entre el ordenamiento europeo y el del Estado miembro, es objeto inmediato de discusión la relación entre la Constitución europea y la Constitución de los Estados miembros, que conjuntamente realizan un "orden constitucional bipolar» ${ }^{51}$. La homogeneidad, al garantizar la efectiva posibilidad de un ordenamiento autónomo de los Estados miembros, representa el centro de dicha bipolaridad, y está en condiciones de dar sentido al entero sistema europeo, contribuyendo a su estabilización desde el punto de vista del Derecho constitucional ${ }^{52}$.

Si se repara en el contenido de esta garantía para las Constituciones de los Estados miembros, puede decirse que ésta se concreta en la libertad de organizar el Estado, o sea, la estructura fundamental, política y constitucional, a la que hace referencia el artículo l-5.1 del Tratado constitucional, incluido el sistema de autonomías locales y regionales. Dicho de otro modo, cada Estado miembro, por medio de su propia Constitución, construye su propia democracia y su propio Estado de Derecho, no siguiendo un tipo de democracia y de Estado de Derecho predeterminado.

Por otra parte, parece posible efectuar un discurso análogo con respecto a la parte programática que viene prevista en cada Constitución y que atañe a los desarrollos futuros de las funciones estatales. A estas

51 F.W. SchARPF, Un ordine costituzionale bipolare, en Europa/Europe, 1994, 94 ss., para quien «una Unión Europea no puede desarrollarse siguiendo el esquema de un Estado-nación, ni siquiera federal. Si quiere sobrevivir, debe respetar y proteger la vitalidad y la autonomía de sus componentes constitutivas, en su diversidad institucional y cultural, y ello de modo todavía más acentuado de lo que sucede habitualmente en los Estados federales".

52 Sobre este punto, I. PERNICE, Europäisches und nationales Verfassungsrecht, en VVDStRL 60, Berlin-New York, 2001, 148 ss., en particular, 184 ss. 
prescripciones de las Constituciones de los Estados miembros ha sido legada la fortuna del Estado social en la Europa occidental, en contraposición a los sistemas de economía planificada. En estas prescripciones permanece anclada la especificidad social de cada Estado miembro que ya formaba parte de la Unión, que se haya adherido hace poco o que se adhiera en el futuro. Con respecto a la disponibilidad reservada a los Estados miembros, en este ámbito, el principio de homogeneidad se plantea como "instrumento de salvaguarda de los cometidos y de los fines más altos de la Unión»" ${ }^{53}$, que son los indicados en "una sociedad caracterizada por el pluralismo, la no discriminación, la tolerancia, la justicia, la solidaridad y la igualdad entre mujeres y hombres" y, si se quiere, también en los objetivos contemplados en el artículo $1-3^{54}$.

Pero el aspecto más significativo sigue pareciendo otro, y se refiere a las relaciones entre la Unión y sus ciudadanos, quienes pro parte qua son asimismo los ciudadanos de los Estados miembros. Mediante la homogeneidad, efectivamente, se acoge en el sistema europeo el principio de doble nivel de tutela de los derechos fundamentales. A este respecto, además del llamamiento al respeto de la dignidad humana, a la libertad, a la igualdad y al respeto de los derechos humanos, considerados como elementos del principio, el artículo l-9 del Tratado constitucional hace llamamiento a los derechos fundamentales incorporados en la parte II de la Constitución (pár. 1), prescribe la adhesión de la Unión al Convenio Europeo de Derechos Humanos (pár. 2), y retoma la previsión, ya contenida en el artículo 6.2 TUE, sobre los derechos fundamentales resultantes de las tradiciones constitucionales comunes a los Estados miembros ${ }^{55}$.

${ }^{53}$ Así, H. TRIEPEL, Die Reichsaufsicht. Untersuchungen zum Staatsrecht des Deutschen Reiches, Berlin, 1917, 441, 444, y véase asimismo su incipit en pág. 1 («die Verteilung der materiellen und formellen Zuständigkeiten unter die zwei [Bundesstaat e Bundesglieder], zur gemeinsamen Arbeit am Staatszwecke berufenen Gemeinschaften bildet den vornehmsten Inhalt des 'Gesamtplanes', der das Grundverhältnis zwischen Bundesstaat und Gliedstaat beherrscht»).

${ }^{54}$ F. SoRRENTINO, L'influenza del diritto comunitario sulla Costituzione italiana, en Studi in onore di Leopoldo Elia, Milano, 1999, II, 1635 ss., alerta sobre el peligro que para los principios del Estado social que caracterizan a la Constitución italiana, comportan los principios de una economía de mercado previstos por el ordenamiento europeo. Si embargo, se subraya que, en realidad, se trata de una tensión que puede resolverse sin necesidad de la transformación "de la utilidad social en libertad de empresa", por cuanto "se plantea un problema de ponderación entre los diversos valores", a los que no resultan extrañas las diversas modalidades que para su consecución vienen consignadas en el Derecho europeo (pp. 1653-1655).

55 ... que forman parte del Derecho de la Unión como principios generales, al igual que aquellos derechos fundamentales que garantiza el Convenio Europeo para la Protección de los Derechos Humanos y de las Libertades Fundamentales.

(C) UNED. Revista de Derecho Político 
Desde este punto de vista, el propio significado susceptible de ser atribuido a esta última disposición parece revelarse ahora diverso rspecto a aquel que el Tribunal de Justicia le había conferido en su jurisprudencia, por cuanto el llamamiento a las tradiciones constitucionales comunes ya no desempeña una función supletoria respecto a las lagunas del Derecho europeo, sino - a la luz asimismo del canon de interpretación de los derechos en armonía con las citadas tradiciones (artículo Il-112.4 del Tratado constitucional)— una función de ponderación, a tenor asimismo del principio de primacía del Derecho europeo (artículo I-6 del Tratado constitucional), sobre la base de la concurrencia de los sistemas de tutela (de la Unión y de los Estados miembros) y del principio de la garantía más favorable ${ }^{56}$.

\section{LA VIOLACIÓN DEL PRINCIPIO DE HOMOGENEIDAD}

La Unión se declara «abierta a todos los Estados europeos que respeten sus valores y se comprometan a promoverlos en común" (artículo l-1.2 del Tratado constitucional) y hace del respeto a los valores la condición de admisibilidad para la adhesión (artículo l-58.1 del Tratado constitucional) $^{57}$.

Pero, ¿qué sucede si un Estado miembro no respeta los valores contemplados en el artículo l-2 de la Constitución europea? ${ }^{58}$

${ }^{56}$ Sobre estas bases puede sostenerse tranquilamente que ha sido superada la necesidad de una verificación del ordenamiento europeo, en nombre de los derechos fundamentales, que la Corte Constitucional italiana y el Tribunal Constitucional Federal alemán habían reservado a su jurisdicción.

57 Sobre el procedimiento de adhesión, véase art. I-58.2 del Tratado constitucional: «Todo Estado europeo que desee ser miembro de la Unión dirigirá su solicitud al Consejo. Se informará de esta solicitud al Parlamento Europeo y a los Parlamentos nacionales. El Consejo se pronunciará por unanimidad, previa consulta a la Comisión y previa aprobación del Parlamento Europeo, que se pronunciará por mayoría de los miembros que lo componen. Las condiciones y el procedimiento de admisión se establecerán por acuerdo entre los Estados miembros y el Estado candidato. Este acuerdo deberá ser sometido a ratificación por todos los Estados contratantes, de conformidad con sus respectivas normas constitucionales".

58 Una ulterior cuestión se refiere al modo de entender el frustrado respeto de los valores, ya sea en sentido meramente formal (por ejemplo, con la adopción de actos legislativos que modifiquen el ordenamiento del Estado miembro, convirtiéndolo en no homogéneo respecto al Derecho europeo), ya sea en sentido sustancial (como la alteración de la vida institucional del Estado miembro que, más allá de las modificaciones legislativas del propio ordenamiento, se desenvuelva de manera disconforme con los caracteres del principio de homogeneidad). La respuesta 
La cuestión entronca directamente con la eficacia del principio de homogeneidad en el sistema constitucional europeo y con los poderes de que puede hacer uso la Unión respecto a los Estados miembros, que son obviamente poderes de intromisión en los asuntos de estos últimos y que se justifican en el cometido que tiene la Unión de tutelar su propio ordenamiento y, por ello mismo, de actuar para la conservación, la tutela y la seguridad de la misma Unión ${ }^{59}$.

Históricamente, la introducción del principio de homogeneidad (en el Tratado de Ámsterdam) ha conllevado asimismo la previsión de un procedimiento sancionador, sobre la base del cual correspondería al Consejo, reunido en su formación de Jefes de Estado o de Gobierno, constatar, por unanimidad, "la existencia de una violación grave y persistente por parte de un Estado miembro de los principios contemplados en el apartado 1 del artículo 6». La propuesta motivada, mediante la cual se inicie el procedimiento, correspondería a un tercio de los Estados miembros o a la Comisión, y sería discutida y deliberada «tras invitar al Gobierno del Estado miembro de que se trate a que presente sus observaciones" y "previo dictamen conforme del Parlamento Europeo" (artículo 7.1 TUE) ${ }^{60}$. Superada la fase de la constatación el Consejo, por mayoría cualificada, podía decidir que se suspendieran determinados derechos derivados de la aplicación del Tratado al Estado miembro de que se tratara, «incluidos los derechos de voto del representante del Gobierno de dicho Estado miembro en el Consejo" (artículo 7.2, párrafo 1, TUE) ${ }^{61}$. Obviamente, el Consejo posteriormente, siempre por mayoría cualificada, podía decidir la modificación o la revocación de las medidas adoptadas, "como respuesta a cambios en la situación que motivó su imposición" (artículo 7.3 TUE). Para el Estado miembro sancionado continuarían "en cualquier caso, siendo vinculantes las obligaciones que derivan del Tratado».

parece ir más bien en la segunda dirección, estando el principio de homogeneidad estrechamente conectado con la realidad constitucional de un Estado.

59 Véase C. ScHmIT, La dottrina della Costituzione, cit., 483, quien afirma que «las intervenciones de la federación en los asuntos de sus miembros no son por ello mismo una ingerencia extraña, siendo política y jurídicamente posibles y soportables, puesto que la federación se basa en una afinidad de naturaleza sustancial de los miembros».

${ }^{60}$ A tenor del pár. 6, la deliberación del Parlamento Europeo debería ser adoptada "por mayoría de dos tercios de los votos emitidos, que representen la mayoría de los miembros que lo componen".

${ }^{61}$ La disposición se completa con el siguiente inciso: «Al proceder a dicha suspensión, el Consejo tendrá en cuenta las posibles consecuencias de la misma para los derechos y obligaciones de las personas físicas y jurídicas». El pár. 4, a continuación, determinaba la mayoría cualificada con remisión al art. 205 TCE. 
Este entramado procedimental, que establece una forma de "coacción federal» (Bundeszwang) europea, entró en crisis tras el caso austríaco del año 2000, el cual se resolvió con una toma de posición de los entonces otros catorce Estados miembros de la Unión, con un proceder diverso al previsto por el artículo 7 TUE, y que condujo a un aislamiento jurídicamente (y también políticamente) injustificado de Austria. El caso es que, posteriormente, mediante un procedimiento no previsto por los Tratados, fue constituida una Comisión de sabios, con el fin de redactar un "Informe sobre el estado de la democracia en Austria" en el cual, entre otras cosas, se recomendaba adoptar "procedimientos preventivos de análisis en el ámbito del artículo 7 TUE, de modo que una situación similar a la presente en Austria pueda ser afrontada en el seno de la Unión Europea desde sus primeras manifestaciones" ${ }^{62}$.

Sobre estas bases, con el Tratado de Niza (2001), antes que nada, se procedió a introducir al inicio del artículo 7 TUE un nuevo apartado mediante el cual se disciplina, antes de poner en marcha el procedimiento de "constatación" de la existencia de una violación del principio de homogeneidad, la hipótesis de verificar la existencia de un «riesgo claro de violación grave por parte de un Estado miembro de principios contemplados en el apartado 1 del artículo 6 y dirigirle recomendaciones adecuadas $"^{63}$. Se establece asimismo en esta fase preventiva la obligación de oír al Estado miembro interesado y se prevé -Austria docet- la posibilidad de usolicitar a personalidades independientes que presenten en un plazo razonable un informe sobre la situación en dicho Estado miembro" ${ }^{64}$.

En segundo lugar, se prevé además una adición al artículo 46 TUE, la letra e), merced a la cual se atribuye al Tribunal de Justicia sobre "las disposiciones exclusivamente procedimentales contenidas en el artículo 7, pronunciándose el Tribunal de Justicia a petición del Estado miembro de que se trate y en el plazo de un mes a partir de la fecha de la constatación del Consejo prevista en dicho artículo". De este modo, podemos decir que se ha pasado de una previsión de "coacción fede-

62 Véase Rapporto sullo stato della democrazia in Austria, trad. it., en V. ATRIPALDI - R. Mıccù (coord.), L'omogeneità costituzionale nell'Unione Europea, cit., 209-210.

63 El poder de propuesta (motivada) corresponde a un tercio de los Estados miembros, al Parlamento Europeo o a la Comisión, y la medida preventiva es adoptada por el Consejo, por mayoría de cuatro quintos de sus miembros y previo dictamen conforme del Parlamento Europeo.

${ }^{64}$ Se prevé además que «El Consejo (compruebe) de manera periódica si los motivos que han Ilevado a tal constatación siguen siendo válidos" (art. 7.1, apartado 2, TUE). 
ral» (Bundeszwang) a una previsión de "ejecución federal» (Bundesexekution $)^{65}$.

La Constitución europea ha reelaborado este modelo de ejecución federal, previendo tres fases distintas, en las cuales se ejercen las siguientes competencias con la finalidad de: a) constatar la existencia de un riesgo claro de violación grave por parte de un Estado miembro de los valores contemplados en el artículo I-2 del Tratado constitucional (competencia del Consejo) ${ }^{66}$; b) constatar la existencia de una violación grave $y$ persistente por parte de un Estado miembro de los valores contemplados en el artículo l-2 del Tratado constitucional (competencia del Consejo Europeo) ${ }^{67}$; c) poder adoptar la suspensión frente al Estado miembro en cuestión de algunos de los derechos derivados de la aplicación de la Constitución, incluidos los derechos de voto del miembro del Consejo que represente a dicho Estado (competencia del Consejo) ${ }^{68}$.

65 Para una visión de conjunto de las categorías citadas, véase $H$. KELSEN, L'esecuzione federale. Contributo alla teoria e alla prassi dello Stato federale, con particolare riguardo alla costituzione del Reich tedesco e alla costituzione federale austriaca, 1927, trad.it., en ID., La Giustizia costituzionale, Milano, 1981, 72 ss..

66 Véase Art. I-59.1 del Tratado constitucional, que reconoce a un tercio de los Estados miembros y al Parlamento Europeo un poder de iniciativa motivada, mientras a la Comisión un poder de propuesta. El Consejo puede adoptar una decisión europea (esto es, un acto no legislativo obligatorio en todos sus elementos y, si designa destinatarios, obligatoria únicamente respecto a éstos). El Consejo se pronuncia por mayoría de cuatro quintos de sus miembros, previa aprobación del Parlamento Europeo (las votaciones del Parlamento Europeo, de conformidad con el art. I-59.6 del Tratado constitucional, se efectúan por mayoría de los dos tercios de los votos expresados, que representen la mayoría de los miembros que lo componen).

67 Véase Art. I-59.2 del Tratado constitucional, que reconoce a un tercio de los Estados miembros el poder de iniciativa y a la Comisión el de propuesta. El Consejo Europeo puede adoptar una decisión europea, decidiendo por unanimidad, previa aprobación del Parlamento europeo (véase asimismo art. I-59.6 del Tratado constitucional).

68 Véase Art. 1-59.3 del Tratado constitucional: sobre la base de la constatación prevista en el apartado 2, el Consejo puede adoptar, por mayoría cualificada, una decisión europea que suspenda determinados derechos derivados de la aplicación de la Constitución al Estado miembro de que se trate. "El Consejo tendrá en cuenta las posibles consecuencias de tal suspensión para los derechos y obligaciones de las personas físicas y jurídicas". Por mayoría cualificada se entiende, al menos, el 72\% de los miembros del Consejo que represente a Estados miembros participantes que reúnan como mínimo el $65 \%$ de la población de dichos Estados (según el artículo l-59.5 del Tratado constitucional: «La abstención de los miembros presentes o representados no obstará a la adopción de las decisiones europeas contempladas en el apartado $2 »)$. 
La Constitución prevé que en los procedimientos sea oído siempre el Estado miembro afectado ${ }^{69}$, y confía al Consejo la tarea de supervisar la situación en que hayan quedado las relaciones entre la Unión y dicho Estado miembro ${ }^{70}$.

Durante todo el procedimiento no queda el Estado miembro exento de la observancia de las "obligaciones que le incumben en virtud de la Constitución ${ }^{71}$, quedándole abierta a aquél, así, la posibilidad de recurrir ante el Tribunal de Justicia, el cual es "competente para pronunciarse sobre la legalidad de un acto adoptado por el Consejo Europeo o por el Consejo en virtud del artículo l-59». En tal hipótesis, sería objeto de enjuiciamiento la "constatación del Consejo Europeo o del Consejo", y el parámetro se referiría al "respeto de las disposiciones de procedimiento establecidas en el citado artículo" (artículo III-371 del Tratado constitucional $)^{72}$.

69 Véase art. I-59.1 del Tratado constitucional: «Antes de proceder a esta constatación, el Consejo oirá al Estado miembro de que se trate y por el mismo procedimiento podrá dirigirle recomendaciones"; y art. I-59.2: "tras invitar a dicho Estado miembro a que presente sus observaciones al respecto".

70 Véase art. I-59.1 del Tratado constitucional: «El Consejo comprobará de manera periódica si los motivos que han dado lugar a dicha constatación siguen siendo válidos" y art. I-59.4 del Tratado constitucional: "El Consejo podrá adoptar, por mayoría cualificada, una decisión europea que modifique o derogue las medidas adoptadas en virtud del apartado 3, como respuesta a cambios en la situación que motivó la imposición de las mismas".

71 Obviamente, el Estado miembro interesado no puede participar en la votación sobre la constatación y verificación de las violaciones del principio de homogeneidad, no viniendo efectuado entonces el cálculo sobre la base del tercio o de los cuatro quintos de los Estados miembros a los que se refieren los párrafos 1 y 2 (art. I59.5 del Tratado constitucional) y "Cuando, a raíz de una decisión de suspensión del derecho a voto adoptada de conformidad con el apartado 3, el Consejo se pronuncie por mayoría cualificada con arreglo a una de las disposiciones de la Constitución, esta mayoría cualificada se definirá de la misma manera que en el segundo párrafo o, si el Consejo actúa a propuesta de la Comisión o del Ministro de Asuntos Exteriores de la Unión, como un mínimo del $55 \%$ de los miembros del Consejo que represente a Estados miembros participantes que reúnan como mínimo el $65 \%$ de la población de dichos Estados. En este último caso, una minoría de bloqueo estará compuesta al menos por el número mínimo de miembros del Consejo que represente más del $35 \%$ de la población de los Estados miembros participantes, más un miembro, a falta de lo cual la mayoría cualificada se considerará alcanzada» (art. I59.5, párrafo 4 del Tratado constitucional).

72 «Esta petición deberá presentarse en el plazo de un mes a partir de la constatación. El Tribunal se pronunciará en el plazo de un mes a partir de la fecha de la petición". 
Llegados a este punto, puede concluirse que, también en lo atinente a la sanción infligida por la violación del principio de homogeneidad, se ha producido en el ordenamiento europeo una tendencia a la federalización. En efecto, ésta resultaría del mantenimiento del punto de llegada establecido en el Tratado de Niza, que había transformado la previsión del artículo 7 TUE pasando de ser expresión de la Bundeszwang a expresión de la Bundesexekution; y no solamente por la previsión según la cual "en cualquier caso, este Estado seguirá vinculado por las obligaciones que le incumben en virtud de la Constitución", una condición, ésta, necesaria para poder considerar las medidas adoptadas como sanciones de Derecho público (interno) de la Unión con respecto a un Estado miembro y no como medida de Derecho internacional ${ }^{73}$, sino sobre todo poder haber introducido un procedimiento judicial de control de lo acordado por el Consejo Europeo, apareciendo esta última previsión como imprescindible para considerar todo el instituto como dimanante de la ejecución federal en lugar de representar una forma de coerción respecto al Estado miembro afectado ${ }^{7475}$.

\section{LA HOMOGENEIDAD Y LA PREVALENCIA DEL DERECHO EUROPEO}

La homogeneidad apunta a regular las relaciones entre Unión y Estados miembros. Ante todo, entre la Constitución europea y las Cons-

${ }^{73}$ Véase C. SchmitT, La dottrina della Costituzione, cit., 496-97.

${ }^{74}$ Véase H. KelSEN, Die Bundesexekution, cit., 160 ss.; ID., Verfassungs- und Verwaltungsgerichtsbarkeit im Dienste des Bundesstaates, nach der neuen österreichischen Bundesverfassung vom 1. Oktober 1920, en ZSR, 1923, 173 ss.

${ }^{75}$ Con la Constitución europea vienen a fusionarse las dos entidades distintas, aunque vinculadas, de la Unión Europea y de la Comunidad Europea, en una sola persona (véase art. I-7 del Tratado constitucional, a tenor del cual "La Unión tiene personalidad jurídica»), así como sus respectivos tratados; puede decirse, así, que deja de existir la distinción entre método intergubernamental y método comunitario, si bien permanece en algunas hipótesis la decisión del Consejo Europeo por unanimidad, que asume un significado diverso. Este aspecto, en efecto, con la Constitución cesa de ser un perfil equívoco de las relaciones supranacionales y se convierte en un acto de Derecho público. En lo que atañe a la problemática que aquí nos ocupa, puede observarse que en caso de violación del principio de homogeneidad, por no haber tenido la debida acogida el principio contemplado en el art. I-59 del Tratado constitucional, a diferencia de lo que sucedía en el sistema de los tratados, sería aplicable a las relaciones entre Unión y Estado miembro, lo dispuesto en los arts. III-360 a III-363 del Tratado constitucional (ex arts. 226-229 TCE), que consignan una forma de ejecución federa que afecta al conjunto del ordenamiento europeo. 
tituciones de los Estados miembros. Aquélla, una vez asumido su carácter vertical, expresa una supremacía del ordenamiento constitucional sobre el ordenamiento de los Estados miembros.

Conviene aclarar el concepto de "supremacía" que se adopta en las relaciones internas de los ordenamientos complejos, en donde operan más niveles constitucionales y legislativos, desde el momento en que esa supremacía no es expresión de un jerarquización de las relaciones entre Unión y Estados miembros, sino - mucho más- un ulterior reforzamiento del vínculo supranacional que se expresa como vínculo al respeto del Derecho europeo. El tema de la supremacía se erige así en una relación entre ordenamientos regulada por el Derecho, lo cual a su vez significa que afecta directamente a las fuentes del Derecho de los respectivos ordenamientos: las fuentes de la Unión y las de los Estados miembros; Constitución y leyes europeas de un lado y, de otro, Constitución y leyes estatales.

En este contexto, el principio de homogeneidad expresa una parte de la supremacía europea, pero no la agota. Junto a ella, en efecto, se sitúa de modo complementario y con objeto de articular el sistema, el principio de primacía del Derecho europeo formulado expresamente por el artículo I-6 del Tratado constitucional, a tenor del cual «la Constitución y el Derecho adoptado por las instituciones de la Unión en el ejercicio de las competencias que se le atribuyen a ésta primarán sobre el Derecho de los Estados miembros".

Repárese en que, del mismo modo que la primacía del Derecho europeo no comporta la anulación del ordenamiento del Estado miembro y de sus fuentes, puede decirse que la disposición constitucional que la prescribe no representa sino una norma tendente a asegurar una (más amplia) homogeneidad de los ordenamientos en el marco de la Constitución europea, que operaría en caso de colisión de normas (europeas y estatales) resolviendo las antinomias.

Esta circunstancia debería ya poner de manifiesto que entre principio de homogeneidad y principio de primacía subsisten múltiples conexiones. Y no está de más precisar que las relaciones que determinan los dos principios son diversas de las que se originan como consecuencia del reparto de competencias expresamente disciplinado por el Título III de la Constitución, aunque se refieran casi siempre al ejercicio de competencias.

Ahora bien, si la norma sobre la homogeneidad prescribe los principios estructurales que deben ser respetados por los ordenamientos de los Estados miembros, a fin de que el entero sistema europeo 
(Unión, más Estados miembros) pueda ser capaz de realizar los objetivos de la Unión (previstos por el artículo l-3 del Tratado constitucional), y el principio establecido en el artículo l-6 del propio Tratado constitucional prescribe que la Constitución europea prevalece sobre el Derecho de los Estados miembros, de todo ello habría que extraer la conclusión de que la autonomía (constitucional) asegurada a los Estados miembros por el principio de homogeneidad en la definición de su "forma", no debe llevar en ningún caso a mandatos jurídicos (constitucionales, o legislativos) que puedan resultar un obstáculo para el cumplimiento de las normas de la Constitución europea ${ }^{76}$.

Pero esto no es todo. La norma constitucional del artículo l-6 prevé que sobre el Derecho de los Estados miembros no prevalezca sólo la Constitución, sino asimismo el Derecho adoptado por las instituciones de la Unión en el ejercicio de las competencias; lo cual viene a significar que sobre los Estados miembros pesa una ulterior obligación: la de no obstaculizar el cumplimiento del Derecho europeo (secundario, u ordinario) con normas, incluso constitucionales, del ordenamiento interno ${ }^{77}$. La única condición, para esta segunda obligación, radica en que el acto normativo europeo sea conforme con las reglas sobre competencia establecidas por la Constitución.

Con este presupuesto, el proprium del principio del primacía del artículo I-6 parece residir exactamente en esto: que el principio establece la directa eficacia y validez de la Constitución y del Derecho europeo en la esfera de acción de los Estados miembros, sin necesidad de un acto de ejecución, y de modo vinculante para las autoridades, los jueces y las administraciones de los Estados miembros.

Cabría observar que un principio de este calibre existe ya desde hace tiempo en el Derecho comunitario, gracias a la obra de la jurisprudencia del Tribunal de Justicia ${ }^{78}$, y que el artículo I-6 no innova,

76 Piénsese en la circunstancia de que el contenido de la Constitución de los Estados miembros no depende del punto de vista de las materias afectadas por el reparto de competencias, por lo que en dichas competencias pueden resultar incluidas prescripciones que recaigan en el ámbtio de las competencias europeas y puedan contener repeticiones de reglas del Dereco europeo.

77 Desde este punto de vista, por ejemplo, la Constitución de un Estado miembro puede repetir una norma que prevea la "protección de la competencia» (así, art. 117, apartado 3, letra e, de la Constitución italiana), pero no puede contradecir, a través de los desarrollos de su legislación, el Derecho europeo de la competencia.

78 Basta pensar en la sentencia del Tribunal de Justicia de 4 de febrero de 1963, asunto 26/62, Van Gend \& Loos, en Racc., 1963, 3 ss.; Id., sentencia 15 julio 1964, asunto 6/64, Costa, en Racc., 1964, I, 1131 ss.; Id., sentencia de 9 de marzo 1978, 
puesto que la primacía del Derecho europeo residiría en el mismo presupuesto en el que hasta ahora ha tenido su fundamento el Derecho comunitario, esto es, la voluntad de los Estados miembros de dar vida a una ordenamiento supranacional, y formalmente en las órdenes de ejecución de los Tratados constitutivos, más o menos bajo la égida de normas constitucionales de apertura de sus respectivos ordenamientos internos (por ejemplo: artículo 11 de la Constitución italiana, o artículo 24 de la Ley Fundamental de Bonn).

Sin embargo, se trataría de una reconstrucción que difícilmente puede considerarse exhaustiva de todos los perfiles presentes en el supuesto que nos ocupa; en particular, de un lado, el intento de explicar la primacía del Derecho europeo como un efecto de Derecho internacional - justificada históricamente por la obra del juez comunitario- ha venido siempre contradicho por la circunstancia de que el efecto directo del Derecho europeo articula un poder de intervención directa de la Unión con respecto (y en el seno) de los Estados miembros, el cual constituye la expresión de un poder de Derecho público ${ }^{79}$.

Por otra parte, la circunstancia de que el principio de primacía del Derecho europeo ya no venga deducido de los Tratados, como un principio implícito, sino que resulte formulado en el texto de la Constitución europea, de modo expreso, debería conducir a entender - al menos, ahora- que el fundamento de la primacía, aceptado por los Estados miembros, es precisamente la norma (artículo l-6) de la Constitución europea $^{80}$.

En el sistema constitucional que se delimita, la homogeneidad del ordenamiento de los Estados miembros con los valores de la Unión y la

asunto 106/77, Simmenthal, en Racc., 1978, I, 629 ss. Esta jurisprudencia ha conducido, tras un largo período de colaboración entre el juez comunitario y los jueces constitucionales alemán e italiano, a un modus vivendi, según el cual la primacía del Derecho comunitario ha dado lugar a la mera inaplicación de las normas contradictorias del Derecho interno, sin necesidad de su formal eliminación o declaración de ilegitimidad, y ello en razón de la reconstrucción del sistema sobre la base del esquema de los dos ordenamientos autónomos y coordinados.

79 Así, C. Schmıтt, La dottrina della Costituzione, cit., 497, el cual subraya la superación de la llamada impermeabilidad del ordenamiento interno que caracteriza a las relaciones de Derecho internacional y que reclama la adopción de procedimientos de adaptación.

80 Véase asimismo F. SORRENTINo, I fini dell'Unione europea nel progetto di trattato costituzionale, en AA. VV., Auf dem Weg zu einer europäischen Wissensgesellschaft/Verso una società europea della conoscenza, Villa Vigoni, VIII, 1/2004, 10 ss. e 16. 
aplicación sin obstáculos del Derecho europeo son, por ello mismo, elementos complementarios de la integración, y lo que no venga cubierto por el principio de homogeneidad se sustentará en la aplicación del principio de primacía ${ }^{81}$.

\section{LA HOMOGENEIDAD Y LAS REGLAS DE COMPETENCIA}

Los elementos que constituyen el principio de homogeneidad precisan ser concretados mediante la organización y el desarrollo coherente de las funciones del Estado. El respeto de la dignidad humana, la libertad, la democracia, la igualdad, el Estado de Derecho y el respeto de los derechos humanos, incluidos los derechos de las personas pertenecientes a una minoría, corren el riesgo de quedar vacíos de contenido si la legislación, la administración y la judicatura de un Estado no concurren a su cumplimiento de un modo eficaz ${ }^{82}$.

81 Esta innovación, por ello mismo, desde el punto de vista de la percepción del proceso de integración, no se revela en absoluta secundaria, y da realmente al traste con las objeciones de quien mantiene, basándose en la inaplicación de la ley estatal, que los efectos jurídicos del principio de primacía son demasiado limitados respecto a una relación de Derecho público, por cuanto no está en condiciones de producir - de conformidad con el Derecho europeo- la ilegitimidad de la norma interna.

Por otra parte, prescindiendo de la eventual evolución futura, sobre la que sólo sería posible - para el Estado- formular meras hipótesis, tampoco queda desmentido que la inaplicación de la ley estatal, mediante la que se resuelve la antinomia entre Derecho europeo y Derecho interno, no venga operada sobre la base del control de un vicio que convierte en ilegítima a la misma ley. La opción entre inaplicación y anulación, en efecto, no depende de la existencia o no de un vicio de legitimidad de la ley, sino simplemente de la circunstancia de que la jurisdicción competente esté o no facultada para pronunciar la anulación de la ley.

Otro discurso podría hacerse respecto a la posibilidad de declaración de ilegitimidad por efecto de normas de Derecho interno, que quedan salvaguardadas respecto al proceso de integración europea (como, por ejemplo, el art. 11, en combinación con el art. 117.1 de la Constitución italiana, o el art. 23 de la Ley Fundamental de Bonn). Ahora bien, no debe olvidarse que existe una cierta ambigüedad sobre este punto en el mismo Tribunal de Justicia, que ha pretendido, al menos a partir de su sentencia de 15 de julio de 1964, asunto n. ${ }^{\circ}$ 6/64, Costa, cit., que el Estado miembro procediese a la remoción de la ley estatal contradictoria con el Derecho comunitario.

82 Lo mismo puede decirse con respecto a las tareas que la Constitución europea entiende que deben realizarse en la organización social, por parte de "una sociedad caracterizada por el pluralismo, la no discriminación, la tolerancia, la justicia, la solidaridad y la igualdad entre mujeres y hombres". 
Por añadidura, la homogeneidad actúa como presupuesto para el cumplimiento de los objetivos de la Unión, desde el momento en que éstos sólo pueden alcanzarse si entidades homogéneas (la Unión y los Estados miembros) se distribuyen entre ellos las tareas relativas a ese cumplimiento.

El principio de homogeneidad interactúa, por esta vía, con el reparto de las competencias, previsto por el Título III de la Constitución europea, en el sentido de que deviene condición de la eficacia de éste y garantía de que entre los dos ordenamientos existan relaciones incardinadas en la distribución de las funciones públicas según el canon de la "competencia".

Esta circunstancia queda constata de manera decisiva, de un lado, por la universalidad de los objetivos de la Unión, entre los que se encuentran la paz y el bienestar de sus pueblos (artículo I-3.1 del Tratado

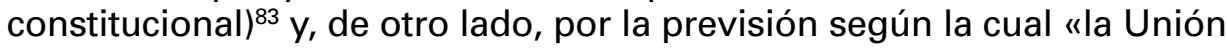
perseguirá sus objetivos por los medios apropiados, de acuerdo con las competencias que se le atribuyen en la Constitución" (artículo l-3.5 del Tratado constitucional).

Sobre este punto, conviene si acaso recordar que toda la Constitución europea está impregnada de una articula regulación de la compe-

${ }^{83}$ La formulación de los objetivos en el art. I-3 de la Constitución resulta tan amplia, que ninguna parte de la vida del Estado puede decirse que quede excluida, en vía de principio, de la ingerencia de la Unión; ésta comprende asimismo: un espacio de libertad, seguridad y justicia sin fronteras interiores y un mercado interior en el que la competencia sea libre y no esté falseada (art. I-3.2 del Tratado constitucional); el desarrollo sostenible de Europa basado en un crecimiento económico equilibrado y en la estabilidad de los precios, en una economía social de mercado altamente competitiva, tendente al pleno empleo y al progreso social, y en un nivel elevado de protección y mejora de la calidad del medio ambiente; la promoción del progreso científico y técnico; la lucha contra la exclusión social y la discriminación y el fomento de la justicia y la protección sociales, la igualdad entre mujeres y hombres, la solidaridad entre las generaciones y la protección de los derechos del niño; la promoción de la cohesión económica, social y territorial y la solidaridad entre los Estados miembros; el respeto de la riqueza de su diversidad cultural y lingüística y la salvaguardia y el desarrollo del patrimonio cultural europeo (art. I-3.3 del Tratado constitucional). En sus relaciones con el resto del mundo, la Unión afirma y promueve sus valores e intereses. Contribuye a la paz, la seguridad, el desarrollo sostenible del planeta, la solidaridad y el respeto mutuo entre los pueblos, el comercio libre y justo, la erradicación de la pobreza y la protección de los derechos humanos, especialmente los derechos del niño, así como al estricto respeto y al desarrollo del Derecho internacional, en particular el respeto de los principios de la Carta de las $\mathrm{Na}$ ciones Unidas (art. I-3.4 del Tratado constitucional). 
tencia que, si por un lado retoma los principios ya ínsitos en los tratados europeos ${ }^{84}$, por otro lado presenta inéditas formulaciones basadas en la necesidad de garantizar efectivamente una articulación de los poderes entre Unión y Estados miembros.

Así, la Constitución, según categorías ya utilizadas en el artículo 5 del Tratado de la Comunidad Europea, pero siguiendo más explícitamente reglas relacionadas con el principio de enumeración de los poderes de la Unión en las cuales resulta evidente - con sus aportaciones positivas y con sus defectos - la contribución de la doctrina alemana del Estado federal, individualiza, en primer lugar, competencias exclusivas de la Unión, esto es, respecto de las cuales "sólo la Unión podrá legislar y adoptar actos jurídicamente vinculantes" y "los Estados miembros, en cuanto tales, únicamente podrán hacerlo si son facultados por la Unión o para aplicar actos de la Unión» (artículo l-12.1 del Tratado constitucional); en segundo lugar, competencias compartidas con las de los Estados miembros, en donde la Unión y los Estados miembros podrán legislar y adoptar actos jurídicamente vinculantes en dicho ámbito, pero los Estados miembros podrán ejercer su competencia en la medida en que la Unión no haya ejercido la suya o haya decidido dejar de ejercerla (artículo l-12.2 del Tratado constitucional) ${ }^{85}$.

${ }^{84}$ Véase, sobre este punto, el art. I-11 del Tratado constitucional (Principios fundamentales), a tenor del cual: «1. La delimitación de las competencias de la Unión se rige por el principio de atribución. El ejercicio de las competencias de la Unión se rige por los principios de subsidiariedad y proporcionalidad. 2. En virtud del principio de atribución, la Unión actúa dentro de los límites de las competencias que le atribuyen los Estados miembros en la Constitución para lograr los objetivos que ésta determina. Toda competencia no atribuida a la Unión en la Constitución corresponde a los Estados miembros. 3. En virtud del principio de subsidiariedad, en los ámbitos que no sean de su competencia exclusiva la Unión intervendrá sólo en caso de que, y en la medida en que, los objetivos de la acción pretendida no puedan ser alcanzados de manera suficiente por los Estados miembros, ni a nivel central ni a nivel regional y local, sino que puedan alcanzarse mejor, debido a la dimensión o a los efectos de la acción pretendida, a escala de la Unión. Las instituciones de la Unión aplicarán el principio de subsidiariedad de conformidad con el Protocolo sobre la aplicación de los principios de subsidiariedad y proporcionalidad. Los Parlamentos nacionales velarán por el respeto de dicho principio con arreglo al procedimiento establecido en el mencionado Protocolo. 4. En virtud del principio de proporcionalidad, el contenido y la forma de la acción de la Unión no excederán de lo necesario para alcanzar los objetivos de la Constitución. Las instituciones aplicarán el principio de proporcionalidad de conformidad con el Protocolo sobre la aplicación de los principios de subsidiariedad y proporcionalidad".

${ }^{85}$ Repárese en que para todas las competencias cabe predicar lo dispuesto por el art. I-12.6 del Tratado constitucional, a tenor del cual «el alcance y las condiciones de 
Sin embargo, prescindiendo de los problemas que planteará y de los desarrollos que conocerá la "política exterior y de seguridad común» ${ }^{86}$, la Constitución europea prevé ulteriores hipótesis de competencia, como la definición de políticas (económicas y ocupacionales) atribuida a la Unión, así como la coordinación de políticas, sobre la base de las normas establecidas por la Constitución, atribuida a los Estados miembros (artículo l-12.3 del Tratado constitucional); o también la previsión de sectores en los que la competencia viene atribuida a la Unión únicamente "para llevar a cabo acciones con el fin de apoyar, coordinar o complementar la acción de los Estados miembros, sin por ello sustituir la competencia de éstos en dichos ámbitos", con la explícita indicación de que "los actos jurídicamente de la Unión adoptados en virtud de las disposiciones de la Parte III relativas a esos ámbitos no podrán conllevar armonización alguna de las disposiciones legales y reglamentarias de los Estados miembros" (artículo I-12.5 del Tratado constitucional). E incluso la misma "cláusula de flexibilidad" (artículo I18 del Tratado constitucional), heredera del principio de los poderes implícitos contenido en el Tratado de la Comunidad (primero artículo 235 y después artículo 308), prevé que la eventual ampliación de poderes decidida (por unanimidad) por el Consejo de Ministros a propuesta de la Comisión y previa aprobación del Parlamento Europeo, no pueda "conllevar armonización alguna de las disposiciones legales y reglamentarias de los Estados miembros cuando la Constitución excluya dicha armonización" (artículo l-18.3 del Tratado constitucional).

\section{Summary:}

1. THE APPARENT DIVERSITY OF THE CONTENT OF THE HOMOGENEITY CLAUSE WITHIN THE TREATY ON EUROPEAN UNION AND THE EUROPEAN CONSTITUTION. 2. THE MERE JURIDICAL NATURE OF HOMOGENEITY AND THE SOCIOLOGICAL NATURE OF ITS FOUNDA-

ejercicio de las competencias de la Unión se determinarán en las disposiciones de la Parte III relativas a cada ámbito".

86 "... incluida la definición progresiva de una política común de defensa" (art. I12.4 del Tratado constitucional), la cual parece superar los cánones de la mera política intergubernamental y se orienta hacia una más estrecha y vinculada política europea (véase asimismo el art. I-16 del Tratado constitucional (Política exterior y de seguridad común), el art. I-40 del Tratado constitucional (Disposiciones particulares relativas a la política exterior y de seguridad común), el artículo l-41 del Tratado constitucional (Disposiciones particulares relativas a la política común de seguridad y defensa), y los artículos incluidos en la Parte III, Título V, Capítulo II, de la Constitución (artículos III-394 a III-313 del Tratado constitucional). 
TIONS. 3. "HOMOGENEITY" AND CONSTITUTION: THE NATURE OF THIS PRINCIPLE, AND LIMITS TO THE REFORM OF THE TREATIES. 4. HOMOGENEITY AND THE QUESTION OF THE SOVEREIGNTY: A CLEAR DISTINCTION OF BOTH PROBLEMATIC QUESTIONS. 5. HOMOGENEITY AS A PART OF THE SAME LEGAL ORDER WHOSE PRINCIPLES ARE SHARED BY THE DOMESTIC LEGAL SYSTEMS: THE DANGERS OF UNIFICATION AND THE IDENTITY OF THE MEMBER STATES. 6. HOMOGENEITY AND THE COMPLEX LEGAL ORDER: THE EUROPEAN CONSTITUTION AND THE CONSTITUTIONS OF THE MEMBER STATES. 7. THE VIOLATION OF THE HOMOGENEITY PRINCIPLE. 8. HOMOGENEITY AND THE SUPREMACY OF THE EUROPEAN LAW. 9. HOMOGENEITY AND THE RULES WITH REGARD TO THE DISTRIBUTION OF COMPETENCES BETWEEN EUROPEAN UNION AND MEMBER STATES.

Title:

"The homogeneity clause in the Treaty on European Union and the European Constitution".

\section{Resumen:}

En esta contribución se efectúa una lectura combinada del principio de homogeneidad previsto en el artículo 6.1 del Tratado de la Unión Europea y en el artículo I-2 del Tratado por el que se establece una Constitución para Europa. Aunque en ambos casos la homogeneidad constituya un principio jurídico, en el artículo l-2 de la Constitución Europea se introducen nuevos perfiles de carácter programático y axiológico, tendentes a regular los comportamientos futuros tanto de la Unión como de los Estados miembros que acentúan la dinámica de la integración europea. Así, la homogeneidad no se limita a constatar las afinidades existentes entre las diversas partes de la Unión, sino que posee un contenido normativo que impone a la Unión y a los Estados miembros una caracterización de sus respectivos ordenamientos según determinados elementos definidos por la Constitución Europea. En todo caso, no puede confundirse homogeneidad con "soberanía europea", ni tampoco es posible considerar el principio de "primacía" del Derecho europeo como equivalente a "soberanía europea»: en efecto, pese a la mayor integración prevista por la Constitución europea, los Estados miembros no han perdido su capacidad (subjetividad) de Derecho internacional, es decir, la "supremacía europea" no es expresión de jerarquización de las relaciones entre la Unión y los Estados miembros, sino una nueva etapa de reforzamiento del vínculo supranacional que traduce una mayor consolidación del respeto del Derecho europeo. Y, 
en ese reforzamiento del vínculo supranacional, juega un papel fundamental el principio de homogeneidad.

\begin{abstract}
:
This paper tackles the homogeneity principle foreseen in Article 6.1 of the Treaty on European Union and in Article I-2 of the Treaty establishing a Constitution for Europe, both provisions being interpreted in conjuction. Though in both cases the homogeneity constitutes a juducial principle, in Article I-2 of the European Constitution there is a new recognition of the homogeneity principle in a programmatical and axiological nature, whose aim is to regulate the future behavioors of both the European Union and of the members states, and as a result, the dynamics of European integration is accentuated. This way, the homogeneity principle does not limit itself to stating the existing affinities between the diverse parts of the European Union, but it has a normative content that it imposes on the Union and the members states, as a characterization of their respective legal orders according to certain elements defined by the European Constitution. In any case, one neither can confuse homogeneity with "European sovereignty", it is also not possible to consider the principle of "supremacy" of European Law as equivalent to "European sovereignty": in effect, in spite of the great integration foreseen by the European Constitution, the member states have not lost their capacity (subjectivity) of International Law, that is to say, "European supremacy" is not an expression of hierarchical structuring of the relations between the Union and the member states, but a new stage of reinforcement of the supranational link that translates a major consolidation of respect for European Law. And, in this reinforcement of the supranational link, the homogeneity principle plays a fundamental role.
\end{abstract}

\title{
Palabras clave.
}

Homogeneidad, soberanía, supremacía, vínculo supranacional, valores eurpeos.

\section{Key words:} values.

Homogeneity, sovereignty, supremacy, supranational link, European 